\title{
Interannual Coupling between Summertime Surface Temperature and Precipitation over Land: Processes and Implications for Climate Change*
}

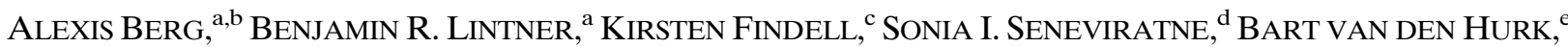 \\ Agnès DuCHARne, ${ }^{\mathrm{f}}$ FrÉdÉRIQUe CHÉRUy, ${ }^{\mathrm{g}}$ STEFAN HAGEMANn, ${ }^{\mathrm{h}}$ DAVID M. LAWRENCE, ${ }^{\mathrm{i}}$ \\ Sergey Malyshev, ${ }^{\mathrm{j}}$ Arndt MeIER, ${ }^{\mathrm{k}}$ AND Pierre Gentine ${ }^{\mathrm{k}}$ \\ ${ }^{a}$ Rutgers, The State University of New Jersey, New Brunswick, New Jersey \\ ${ }^{\mathrm{c}}$ Geophysical Fluid Dynamics Laboratory, Princeton, New Jersey \\ ${ }^{\mathrm{d}}$ Eidgenössische Technische Hochschule Zürich, Zürich, Switzerland \\ ${ }^{\text {e }}$ Royal Netherlands Meteorological Institute, De Bilt, The Netherlands \\ ${ }^{\mathrm{f}}$ UMR METIS, Université Pierre et Marie Curie/Centre National de la Recherche Scientifiques, Paris, France \\ ${ }^{\mathrm{g}}$ Laboratoire de Météorologie Dynamique/L'Institut Pierre-Simon Laplace, Université Pierre et Marie Curie, Paris, France \\ ${ }^{\mathrm{h}}$ Max Planck Institute for Meteorology, Hamburg, Germany

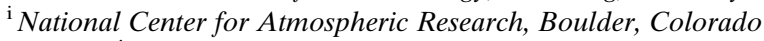 \\ ${ }^{\mathrm{j}}$ Princeton University, Princeton, New Jersey \\ ${ }^{\mathrm{k}}$ Centre for Environmental and Climate Research, Lund University, Lund, Sweden \\ ${ }^{1}$ Columbia University, New York, New York
}

(Manuscript received 30 April 2014, in final form 27 August 2014)

\begin{abstract}
Widespread negative correlations between summertime-mean temperatures and precipitation over land regions are a well-known feature of terrestrial climate. This behavior has generally been interpreted in the context of soil moisture-atmosphere coupling, with soil moisture deficits associated with reduced rainfall leading to enhanced surface sensible heating and higher surface temperature. The present study revisits the genesis of these negative temperature-precipitation correlations using simulations from the Global LandAtmosphere Coupling Experiment-phase 5 of the Coupled Model Intercomparison Project (GLACECMIP5) multimodel experiment. The analyses are based on simulations with five climate models, which were integrated with prescribed (noninteractive) and with interactive soil moisture over the period 1950-2100. While the results presented here generally confirm the interpretation that negative correlations between seasonal temperature and precipitation arise through the direct control of soil moisture on surface heat flux partitioning, the presence of widespread negative correlations when soil moisture-atmosphere interactions are artificially removed in at least two out of five models suggests that atmospheric processes, in addition to land surface processes, contribute to the observed negative temperature-precipitation correlation. On longer time scales, the negative correlation between precipitation and temperature is shown to have implications for the projection of climate change impacts on near-surface climate: in all models, in the regions of strongest temperature-precipitation anticorrelation on interannual time scales, long-term regional warming is modulated to a large extent by the regional response of precipitation to climate change, with precipitation increases (decreases) being associated with minimum (maximum) warming. This correspondence appears to arise largely as the result of soil moisture-atmosphere interactions.
\end{abstract}

\footnotetext{
* Supplemental information related to this paper is available at the Journals Online website: http://dx.doi.org/10.1175/JCLI-D-14-00324.s1.

${ }^{\mathrm{b}}$ Current affiliation: International Research Institute for Climate and Society, Earth Institute at Columbia University, Palisades, New York.

Corresponding author address: Alexis Berg, International Research Institute for Climate and Society, Earth Institute at Columbia University, 61 Rt 9W, Palisades, NY 10964.

E-mail: aberg@iri.columbia.edu
}

\section{Introduction}

Temperature and precipitation are arguably the two most critical components of surface climate over land for both terrestrial ecosystems and human society. The covariability between these two variables and the processes that control or modulate it are thus of great interest to the study of the terrestrial climate variability and change and associated impacts on natural and 
human systems. One issue worth exploring is the extent to which mechanistic understanding of such relationships can inform the interpretation of climate model simulations across multiple temporal and spatial scales and enhance predictive skill.

Anticorrelation of terrestrial surface temperature and precipitation has been observed over a range of time scales and regions in many prior studies. Using station data over 1897-1960, Madden and Williams (1978) demonstrated that seasonal mean temperature and precipitation are negatively correlated in summer over most of North America, especially over the central Great Plains, while correlations of both sign were found roughly equally in other seasons. Similarly, over Europe correlations were found to be positive in winter and negative in summer. Analogous results have been reported using monthly data over North America for the period 1905-84 (Zhao and Khalil 1993) and in regional studies over Europe (Tout 1987; Rebetez 1996) and South America (Rusticucci and Penalba 2000). More recently, Trenberth and Shea (2005) employed reanalysis data and global precipitation observations to extend these results globally: while over the ocean interannual correlations between summertime-monthly temperature and precipitation anomalies tend to be positive, reflecting forcing of precipitation by ocean surface temperature, widespread negative correlations (from the tropics to the high latitudes) are found over land in summer in both hemispheres. Adler et al. (2008) and $\mathrm{Wu}$ et al. (2013) have since demonstrated comparable results using different global observation datasets. Although the studies mentioned above indicate distinct behavior in terrestrial temperature-precipitation covariability for different seasons, Déry and Wood (2005) also report significant anticorrelations between annualmean temperature and precipitation over land for observations over the twentieth century. In addition, Madden and Williams (1978) and Déry and Wood (2005) indicate that such relationships hold across time scales ranging from monthly to decadal. It is thus possible that they modulate trends associated with climate variability or global warming. For instance, Portmann et al. (2009) suggest that a positive trend in precipitation over recent decades may account for the postulated "warming hole" in the southeastern United States.

Figure 1 illustrates these temperature-precipitation correlations over land in summer in a variety of observation datasets-including those used in the studies mentioned above (Trenberth and Shea 2005; Adler et al. 2008; Wu et al. 2013). All datasets are linearly detrended to remove effects of potential trends on correlations and focus on interannual variability. Extensive significant negative correlations dominate over land. The general patterns are robust across datasets: areas of strongest negative correlations include the Sahel, southern Africa, Australia, India, and parts of North America, South America, and Eurasia. Correlations tend to be less significant for shorter records $(30 \mathrm{yr})$ than longer records $(110 \mathrm{yr})$. For shorter time periods, despite general pattern agreement, there are uncertainties between datasets regarding the total extent of these negative correlations (from $32.2 \%$ to $49.7 \%$ of land area). Where correlations are not negative, they are generally insignificant: this is the case mostly in deserts, in some regions at high latitudes, and in the deep tropics. Small areas of positive correlations can be found along the equator, in particular in tropical Africa, in the longer records; however, these patterns appear less robust across datasets, and while field significance (e.g., Livezey and Chen 1983) is achieved for temperature-precipitation correlations as a whole in all datasets, positive correlations are not field significant if considered separately (note that in that case, the threshold for field significance is slightly more than half the value indicated in Fig. 1). Note that while temperature variability is lower at tropical latitudes, precipitation variability tends to be higher in absolute terms (the opposite being true at higher latitudes; e.g., Trenberth and Shea 2005): across latitudes precipitation and temperature thus act to balance each other in terms of the impact of variability on the calculation of correlations.

That summers over land tend to be either warm and dry or cold and wet-but typically not warm and wet or cold and dry-may be interpreted a priori as the result of several candidate processes, as depicted schematically in Fig. 2. First, covariability between summertime temperature and precipitation may simply emerge from synoptic-scale correspondence between decreased cloud cover/precipitation and increased incoming shortwave radiation heating the surface during clear-sky conditions and, conversely, increased cloud cover and decreased surface heating and associated temperatures during rainy conditions. Second, local land-atmosphere interactions, which are expected to play a stronger role in summer (Entekhabi et al. 1992; Koster et al. 2004; Seneviratne et al. 2010), may induce such relationships on seasonal scales through the effect of precipitation on soil moisture and attendant surface heat fluxes. Lower rainfall, for instance, is associated with reduced soil moisture and latent heat flux, and thus increased sensible heating at the surface, resulting in higher near-surface air temperatures (conversely, higher precipitation is associated with lower temperature). Note that this pathway corresponds to the "terrestrial branch" of soil moisture-atmosphere interactions (Guo et al. 2006; Dirmeyer 2011). Positive feedbacks of modified surface heat flux partitioning on 

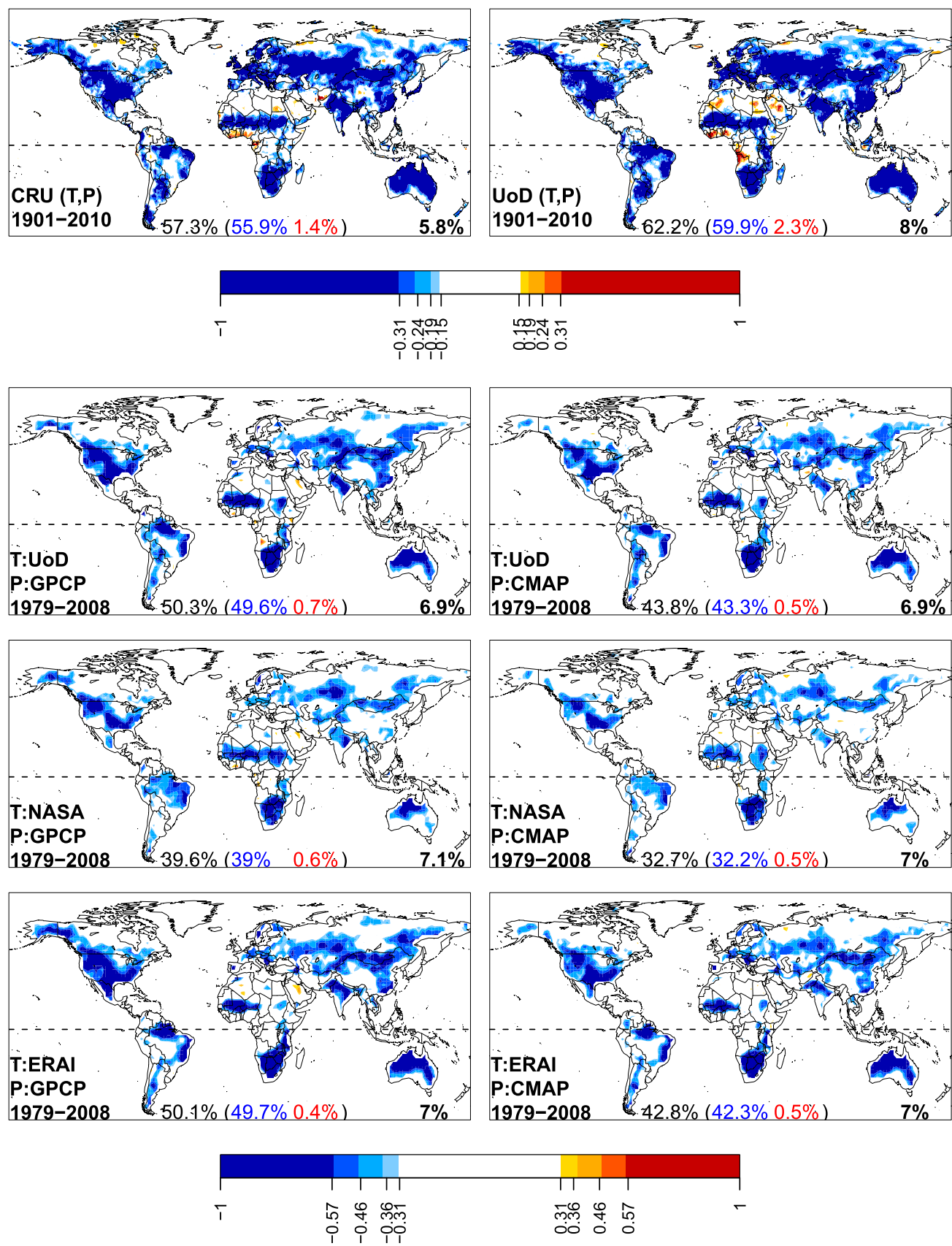

FIG. 1. Point-wise, zero-lag correlations of summertime-mean $T$ against $P$, using different datasets: Climatic Research Unit (CRU) time series (TS) dataset, version 3.21; University of Delaware (UoD) monthly temperature and precipitation dataset version 3.01; National Aeronautics and Space Administration (NASA) Goddard Institute for Space Studies (GISS) Temperature Analysis (GISTEMP); European Centre for Medium-Range Weather Forecasts (ECMWF) Interim Re-Analysis (ERAI); Global Precipitation Climatology Project (GPCP) monthly precipitation dataset, version 2.2; and Climate Prediction Center (CPC) Merged Analysis of Precipitation (CMAP), version 1201. (top) The CRU and UoD datasets use full record lengths, at original resolution $\left(0.5^{\circ} \times 0.5^{\circ}\right)$. All other plots use data regridded on a common $2.5^{\circ} \times 2.5^{\circ}$ grid (1979-2008). Increments on the color scale correspond to the $10 \%, 5 \%, 1 \%$, and $0.1 \%$ levels of correlation significance (for different record lengths) and nonsignificant correlations (at $10 \%$ ) are whited out. Antarctica and Greenland are removed from all datasets. Numbers at the bottom of each panel indicate: center, the land percentage with significant (5\%) $T-P$ correlations (blue for negative correlations only and red for positive correlations) and, right, the field significance threshold, as estimated by a Monte Carlo procedure in which yearly maps of $T$ and $P$ were randomly shuffled 1000 times; the threshold used is the $95 \%$ quantile of the corresponding 1000-member distribution of area percentage with significant (5\%) correlations (e.g., Livezey and Chen 1983). The dashed equatorial line separates JJA means used for the Northern Hemisphere and DJF means used for the Southern Hemisphere. 


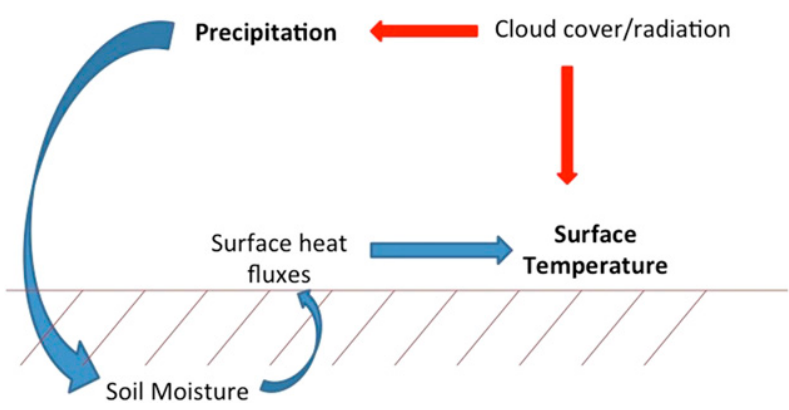

FIG. 2. Simplified representation of two pathways through which correlations between seasonal mean temperature and precipitation can occur in summer: red for atmospheric processes and blue for land-atmosphere interactions. Note that in the interest of clarity, not all physical relationships are depicted here (e.g., impacts of temperature on soil moisture and feedbacks of surface fluxes to cloud cover are not represented).

cloud cover/radiation (e.g., Gentine et al. 2013) and large-scale circulation (e.g., Haarsma et al. 2009) may further amplify the effect of precipitation variability on temperatures.

The impact of soil moisture anomalies on subsequent temperatures has been highlighted in a number of mechanistic modeling studies that have isolated soil moisture variability as a source of daily surface temperature variability in summer, especially in transitions between humid and dry climates (Koster et al. 2006; Seneviratne et al. 2006; Koster et al. 2010). Observation-based estimates of soil moisture-temperature coupling are consistent with these patterns (Miralles et al. 2012). Soil moisture-atmosphere interactions have been shown to play an amplifying role in warm extremes, as noted for recent European heat waves in observational (Vautard et al. 2007; Hirschi et al. 2011; Quesada et al. 2012) as well as modeling (Fischer et al. 2007; Zampieri et al. 2009) studies. Observations provide support for antecedent soil moisture deficits enhancing the probability of subsequent summer hot conditions across different regions of the globe (Durre et al. 2000; Shinoda and Yamaguchi 2003; Mueller and Seneviratne 2012).

These lines of evidence point to coupled landatmosphere processes as the source for the regionally widespread anticorrelations of summertime terrestrial temperature and precipitation (Trenberth and Shea 2005; Koster et al. 2009b). However, whether local land surface processes are solely responsible for the largescale, interannual covariability between summertimeaveraged temperature and precipitation as depicted in Fig. 1 (see also Trenberth and Shea 2005; Adler et al. 2008; Wu et al. 2013) remains to be determined. In their analysis of the relationship between mean summertime temperature and precipitation using a single climate model, Koster et al. (2009b) indicate that these temperature-precipitation anticorrelations essentially disappear when simulated land-atmosphere interactions are disabled by prescribing surface fluxes; they thus identify land-atmosphere processes as the dominant driver of these relationships. Krakauer et al. (2010) also report reduced coupling of temperature and precipitation in another model when soil moisture-atmosphere coupling is suppressed through prescribing soil moisture, although they did not investigate this behavior in detail.

The aim of the present study is to explore more extensively, across several models, the correlations between mean temperature and precipitation in order to untangle the contribution of the different processes illustrated in Fig. 2. To do so, we make use of simulations from the recent phase 5 of the Coupled Model Intercomparison Project (CMIP5) Global Land-Atmosphere Coupling Experiment (GLACE-CMIP5; Seneviratne et al. 2013), in which simulations spanning 1950-2100 were performed with a suite of current-generation models following an experimental setup disabling land-atmosphere interactions. The manuscript is organized as follows: we describe the models and fields analyzed in section 2 . Section 3 presents the temperature-precipitation correlations in the GLACE-CMIP5 simulations. Land and atmospheric controls on these correlations are investigated in section 4 , while section 5 describes the potential relevance of these correlations for climate change projections. The principal results and implications of our study are discussed in section 6.

\section{Methods and datasets}

In the context of the GLACE-CMIP5 experiment, five modeling centers performed a land-atmosphere-only transient climate change simulation (hereafter referred to as "expA") in which total soil moisture was overridden in the respective models by the climatological values over 1971-2000 from the corresponding historical, fully coupled CMIP5 simulation. The simulation expA extends over 1950-2100, with transient sea surface temperatures (SSTs), sea ice, land use, and radiative forcing agent concentrations prescribed from the corresponding CMIP5 simulations [using the historical simulations over 19502005 and the representative concentration pathway 8.5 (RCP8.5) scenario thereafter, characterized by high population and energy consumption growth, no climate policy and unabated emissions]; however, soil moisture in each model is overridden by the 1971-2000 climatological seasonal cycle of soil moisture, and thus maintains a climatological seasonal cycle throughout the transient simulation. For each model, either the fully coupled CMIP5 simulation, or, in cases where there were minor differences in setup, a new reference simulation identical to 
expA but with interactive soil moisture, was considered as a reference simulation (hereafter referred to as "REF"). The five models analyzed here are the Geophysical Fluid Dynamic Laboratory (GFDL) Earth System Model with the Modular Ocean Model (GFDL-ESM2M, hereinafter ESM2M), the National Center for Atmospheric Research (NCAR) Community Climate System Model, version 4 (CCSM4), the European Consortium Earth System Model (EC-EARTH) developed by a consortium of European research institutions (see www.to.isac.cnr.it/ ecearth/), the Max Planck Institute (MPI) for Meteorology Earth System Model (MPI-ESM), and the Institut Pierre-Simon Laplace Coupled Model, version 5A (IPSL-CM5A). The reader is referred to Seneviratne et al. (2013) for further discussion of the models and the experimental protocol of GLACE-CMIP5.

Here we compare interactive (REF) and prescribed (expA) soil moisture simulations over 1971-2000; we focus on correlations between temperature $(T)$ and precipitation $(P)$ in summer calculated, as in Fig. 1, as zero-lag pointwise correlations of summertime-mean temperature against precipitation (hereafter referred to as $T-P$ correlations). Although focusing on 1971-2000 limits sample sizes to 30 paired values (temperature and precipitation for 30 summers), it ensures that both simulations have identical soil moisture climatologies. The comparison thus isolates the effect on climate of soil moisture variability and associated soil moisture-atmosphere interactions only. JuneAugust (JJA) means are used for the Northern Hemisphere and December-February (DJF) means for the Southern Hemisphere. Correlations between other variables are investigated similarly. As in Fig. 1, 30-yr time series of all climate variables analyzed were linearly detrended to remove any spurious effect of climate change-related trends on correlations and focus on interannual variability; such detrending was found to have little quantitative impact on the results for most models. Correlations are presented on the models' native grids, with resolution ranging from $1.125^{\circ} \times 1.125^{\circ}$ for EC-EARTH to $3.75^{\circ} \times 1.875^{\circ}$ for IPSLCM5A. Antarctica and Greenland are removed from all datasets. Computations were performed, and figures generated, with the R software (R Core Team 2012).

\section{Temperature-precipitation correlations}

Figure 3a shows that $T-P$ correlations are generally significantly negative over most of the land surface in REF in all models. The common patterns of negative $T-P$ correlations that emerge across models-for example, the United States, the Sahel, a large swath of Eurasia, and parts of Southeast Asia in JJA; and the Amazon, South Africa, and northern Australia in DJFare in qualitative agreement with calculations based on observations (Fig. 1). Trenberth and Shea (2005) and Wu et al. (2013) indicate similar general agreement from other coupled climate models. Beyond common patterns, Fig. 3a shows that the strength and extent of these correlations vary across models, from strong and widespread correlations (EC-EARTH) to weaker and more diffuse correlations (CCSM4). When combining correlation extent and strength, EC-EARTH shows the strongest negative correlations, followed by ESM2M, MPI-ESM, IPSL-CM5A, and CCSM4 (Fig. 4).

As in observations, areas of positive correlations in models are much reduced compared to areas of negative correlations. However, two models (ESM2M and CCSM4) exhibit coherent patches of significant positive correlations along the equator, over central Africa and Indonesia, that are reminiscent of areas of positive correlations found in some observational datasets (Fig. 1). In ESM2M at least, positive correlations achieve field significance $(4.2 \%$ of land surface area, above the $3.9 \%$ threshold). Thus, model uncertainty seems to parallel observation uncertainty regarding the covariability of temperature and precipitation over land in equatorial regions. Overall, both negative and positive correlations tend to be more significant in models (respectively, 55.4\% and 2.4\% of the land surface area on average across models) than in observations (respectively, $42.8 \%$ and $0.5 \%$ on average across datasets) over comparable 30-yr time periods. This difference may stem from observation uncertainty and the resulting difficulty in diagnosing process-level relationships in observation datasets; we note that results from longer observational record are more consistent with model results (respectively, $57.9 \%$ and $1.9 \%$ of land surface area significantly negatively or positively correlated; see Fig. 1).

The results for simulation expA in Fig. $3 b$ indicate that when soil moisture is prescribed, negative $T-P$ correlations are reduced, in all models, both in extent and intensity. However, while in some models these correlations essentially disappear, becoming less extensive and more disorganized (ESM2M, IPSL-CM5A, and to a lesser extent CCSM4), in others extensive, spatially coherent and significant negative correlations persist (MPI-ESM and EC-EARTH), often in similar regions as in REF. Figure 4 indicates that in terms of combined extent and strength, negative $T-P$ correlations in simulation expA reach $52.2 \%$ and $49.2 \%$, respectively, of those in REF in MPI-ESM and EC-EARTH, but only $18.3 \%, 32.3 \%$, and $26.3 \%$ in ESM2M, CCSM4, and IPSLCM5A, respectively. Using this index, correlations are stronger in EC-EARTH in expA than in CCSM4 in REF.

Positive correlations along the equator in ESM2M and CCSM4 remain in expA, which indicates that they are unrelated to soil moisture variability. We further point out that the spatial extent of positive correlations increases from REF to expA (Fig. 3); positive correlations 
a)

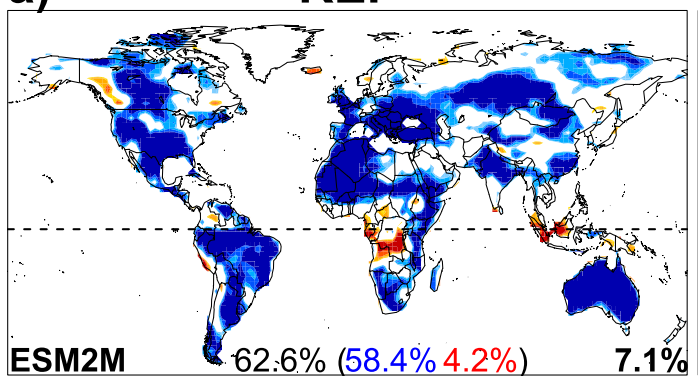

\section{REF}

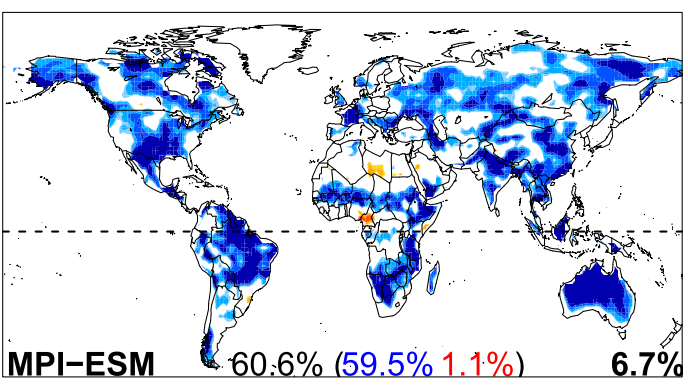

b) $\quad \operatorname{expA}$

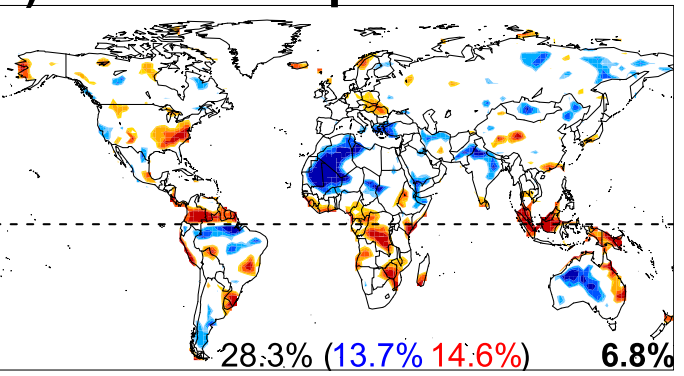

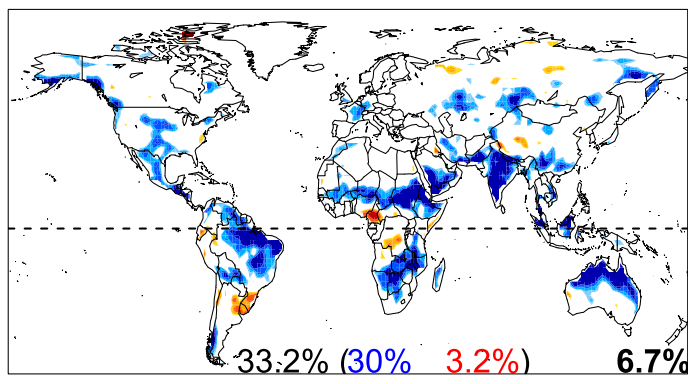
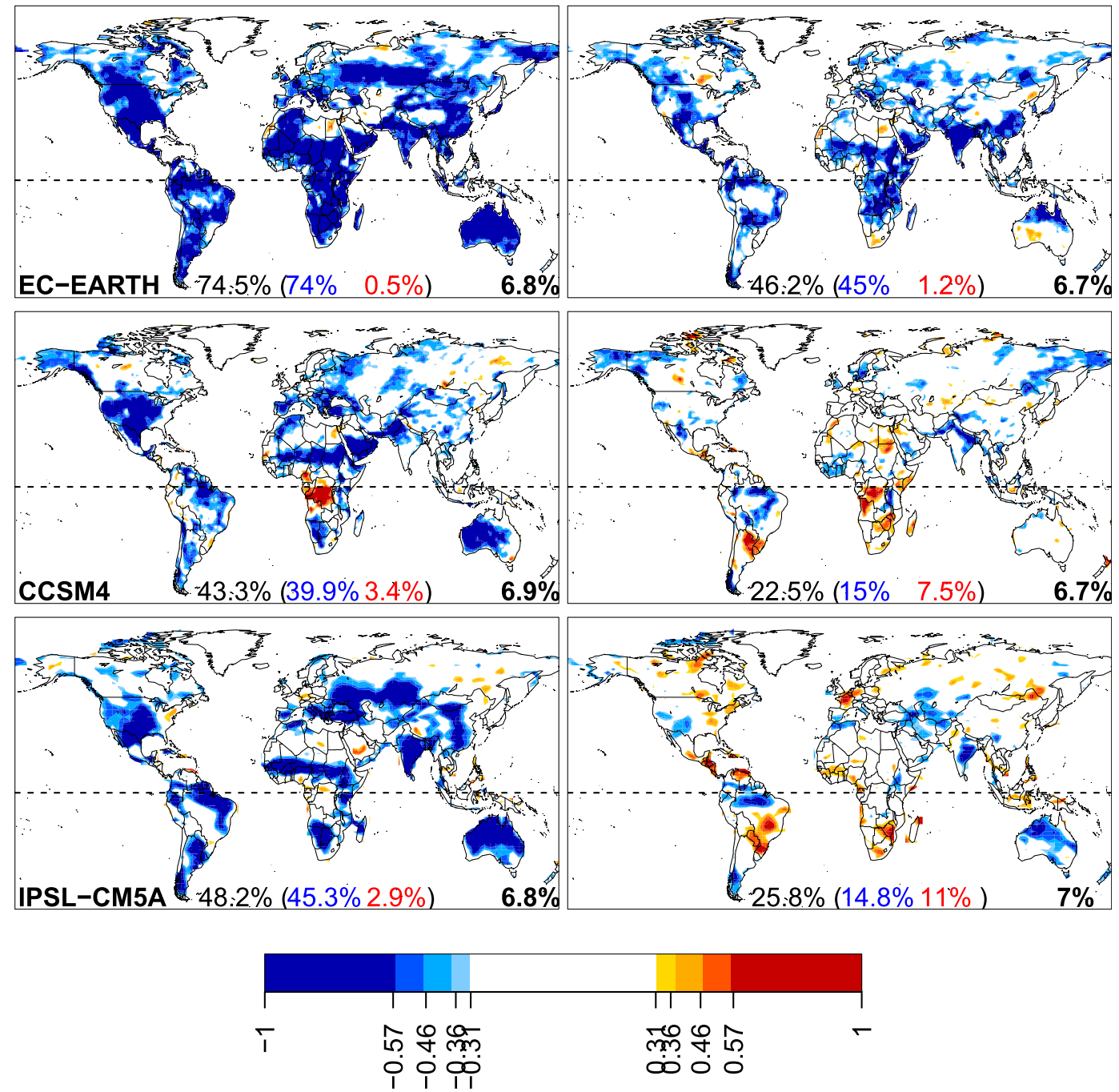

FIG. 3. As in Fig. 1, but for GLACE-CMIP5 models over 1971-2000 in simulations (a) REF and (b) expA. Color key corresponds to the $10 \%, 5 \%, 1 \%$, and $0.1 \%$ levels of correlation significance. 


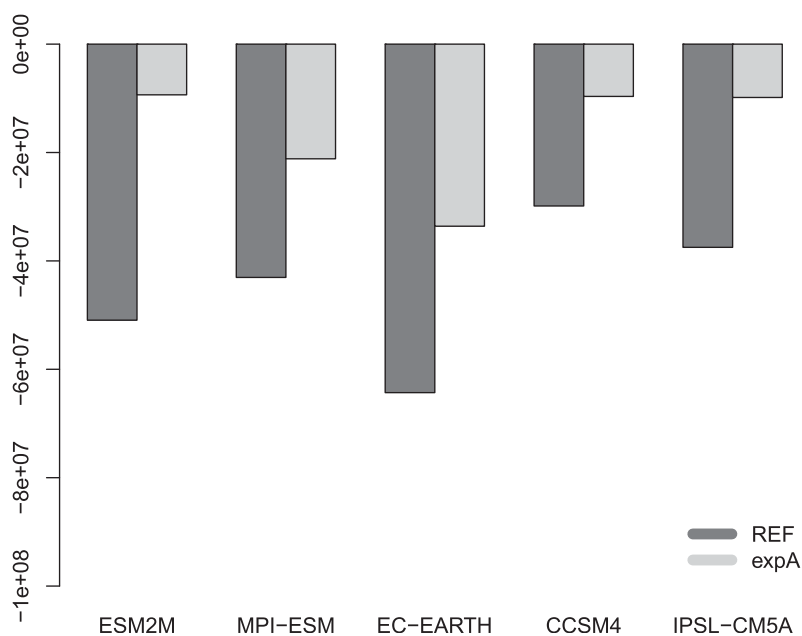

FIG. 4. Sum of the grid cell areas with significant negative $T-P$ correlations (at the $5 \%$ level; i.e., $r=0.36$ ) in simulations REF (dark gray) and expA (light gray), weighted by the $T-P$ correlation values on these grid cells.

achieve field significance in expA in three models (ESM2M, CCSM4, and IPSL-CM5A). Small patches of positive correlations appear in the tropics in expA where insignificant or even negative correlations occurred in REF: this is the case over the eastern part of South America, southern Africa, and Australia, in particular in IPSL-CM5A, CCSM4, and ESM2M. We note that overall, despite the reduction in negative correlations from REF to expA, $T-P$ correlations remain field significant in expA in all models.

Our general a priori interpretation of the differences between simulations REF and expA in Fig. 3 is that soil moisture-atmosphere interactions have been disabled in expA by the suppression of interactive soil moisture. Thus, while all processes represented on Fig. 2 are active in REF and can contribute to simulated $T-P$ covariability, only atmospheric processes play a role in these correlations in $\operatorname{expA}$, and the differences between both simulations reflect the contribution of soil moisture-atmosphere interactions. To confirm this interpretation and further investigate the processes underlying negative $T-P$ correlations in both simulations, we analyze in the following section the different relationships highlighted in Fig. 2 in the different models, on the same interannual seasonalmean time scales as for $T-P$ correlations in Figs. 1 and 3.

\section{Land and atmospheric control on temperature-precipitation correlations}

\section{a. Evaporative regimes}

To highlight the process-level differences between both simulations, we first investigate the different evaporative regimes in REF and expA. In general, evapotranspiration may be either limited by soil moisture availability or by atmospheric demand (temperature, net radiation, vapor pressure deficit, and wind speed); soil moisture's feedbacks to the atmosphere are associated with the soil moisture-limited evaporative regime, when soil moisture controls surface turbulent fluxes and subsequent impacts on the low-level atmosphere (e.g., Seneviratne et al. 2010).

Correlations between seasonal mean soil moisture (SM) and evapotranspiration (ET) in Fig. 5a highlight the average summertime evaporative regime in the different models in REF. Positive correlations indicate that, on average, ET is soil moisture limited (higher soil moisture leading to larger ET). This is the case, generally, in the subtropics and midlatitudes. Conversely, negative correlations point out regions where ET is energy limited: when water supply is sufficient, ET variability is then determined by variations in atmospheric demand, so that ET variability then drives soil moisture variability (e.g., higher ET depleting soil moisture, producing negative SM-ET correlations). This is the case in the tropics, and in high-latitude and high-altitude regions. Large-scale patterns of SM-ET correlations are fairly consistent across models, but correlations vary in amplitude and regional differences can be important. MPI-ESM noticeably exhibits the most positive correlations, and shows almost no negative correlations in the tropics. These intermodel differences arguably reflect the different parameterizations of soil hydrology in the models (Koster et al. 2009a).

Across models, patterns of correlations between summertime mean ET and atmospheric demand, represented here by temperature (Fig. 5b) and incoming solar (shortwave) radiation (Rs; Fig. 5c) are consistent with the above. ET- $T$ correlations are negative where soil moisture limits ET (see Fig. 5a): reduced ET is then offset by higher sensible heat flux, thus leading to higher temperatures (conversely, higher ET damps temperature). In these regions, negative ET-Rs correlations (Fig. 5c) reflect the fact that higher evapotranspiration results from higher rainfall, which is associated with lower solar radiation. Conversely, ET- $T$ and Rs-ET correlations are positive where atmospheric evaporative demand, linked to temperature and surface net radiation, drives evapotranspiration. Comparison between Figs. $5 \mathrm{~b}$ and $5 \mathrm{c}$ shows that in most models the effect of radiation seem to prevail at low latitudes and the effect of temperature at high latitudes. Overall, evaporative regimes in REF as diagnosed in Fig. 5 are consistent with similar analyses using climate models (Seneviratne et al. 2006), observation-driven land surface models (Teuling et al. 2009), or observation-based datasets (Jung et al. 2010). Note that the analysis of the 
a) $\operatorname{cor}(\mathrm{SM}, \mathrm{ET})$

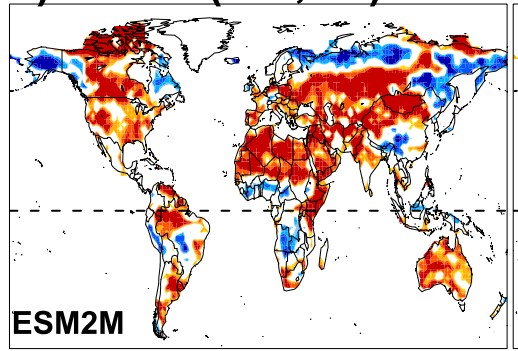

b) $\quad \operatorname{cor}(E T, T)$
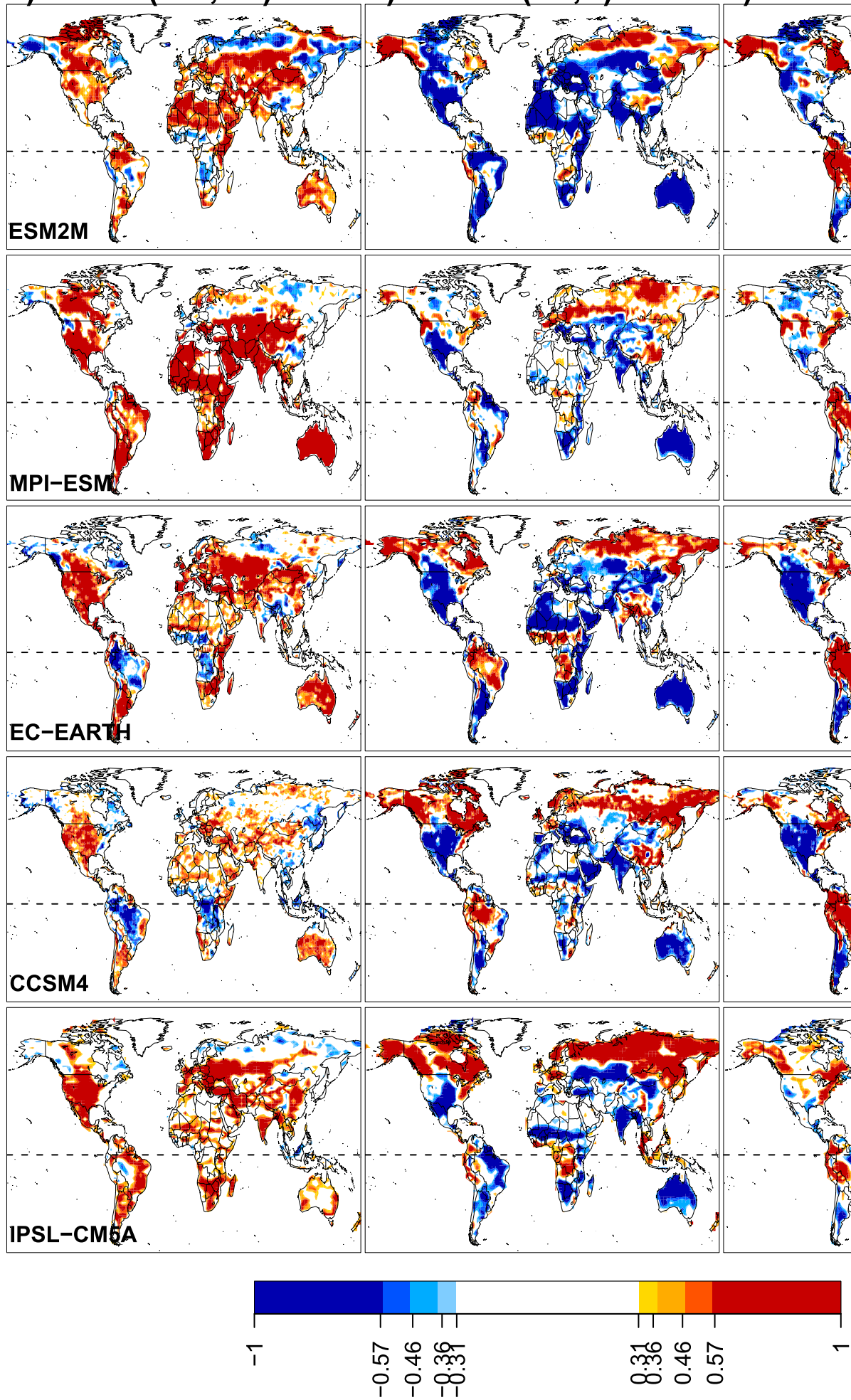

FIG. 5. Correlations between summertime-mean (a) total soil moisture and evapotranspiration, (b) temperature and evapotranspiration, and (c) incoming shortwave radiation and evapotranspiration over 1971-2000 in simulation REF for the different models. Color key corresponds to the $10 \%, 5 \%, 1 \%$, and $0.1 \%$ levels of correlation significance. 
surface or atmospheric control on ET (i.e., latent heat flux) here illustrates the control on surface turbulent heat fluxes, since at the time scale considered here the surface sensible heat flux is strongly anticorrelated with ET in soil moisture-limited regimes and positively correlated in energy-limited regimes. Thus results for Fig. 5 are similar with either surface heat flux or a composite thereof (e.g., Bowen ratio and evaporative fraction).

Results from simulation REF show complementary patterns of soil moisture- and energy-limited evaporative regimes; by contrast, results for simulation expA (Fig. 6) show that when soil moisture variability is prescribed, only atmospheric control on surface ET remains. Figure 6 indicates that atmospheric demand (represented here by incoming shortwave radiation; results with temperature are similar) are driving ET variability nearly everywhere in the different models, except in desert and arid areas where there is little soil moisture to evaporate (note that since the seasonal cycle soil moisture is prescribed in expA and that soil moisture is thus constant from one summer to the next, correlations between soil moisture and ET, similar to Fig. 5a, cannot be computed for expA). This atmospheric control reflects the absence of soil moisture depletion following evapotranspiration in expA, since soil moisture is overridden by climatological values at every time step in the models: in this context, soil moisture exerts no control on ET, and the atmosphere is left to drive ET variability.

The differences in evaporative regimes between REF and expA in Figs. 5 and 6 confirm that while the land surface can feed back to the atmosphere in REF (in regions of soil moisture-limited regime), the atmosphere is entirely driving the land surface in expA. This confirms that soil moisture-atmosphere interactions are playing no role in $T-P$ correlations in simulation expA in Fig. 3 (in particular, in MPI-ESM and EC-EARTH). In the context of Fig. 2, we thus interpret negative $T-P$ correlations in $\operatorname{expA}$ as resulting from the "atmospheric pathway."

\section{b. Atmospheric control on $T-P$ correlations in exp $A$}

The atmospheric pathway involves covariation of cloud cover and rainfall, with reduced rainfall and associated clouds (originated from either changes in largescale circulation or in convection), leading to increased surface solar radiation and increased temperature, and, conversely, increased precipitation/cloud cover leading to reduced incoming solar radiation and temperature. Figure 7 supports this interpretation by showing that regions of negative $T-P$ correlations in simulation expA in Fig. $3 \mathrm{~b}$ are generally collocated (Fig. $7 \mathrm{c}$ ) with regions where precipitation anomalies are significantly anticorrelated
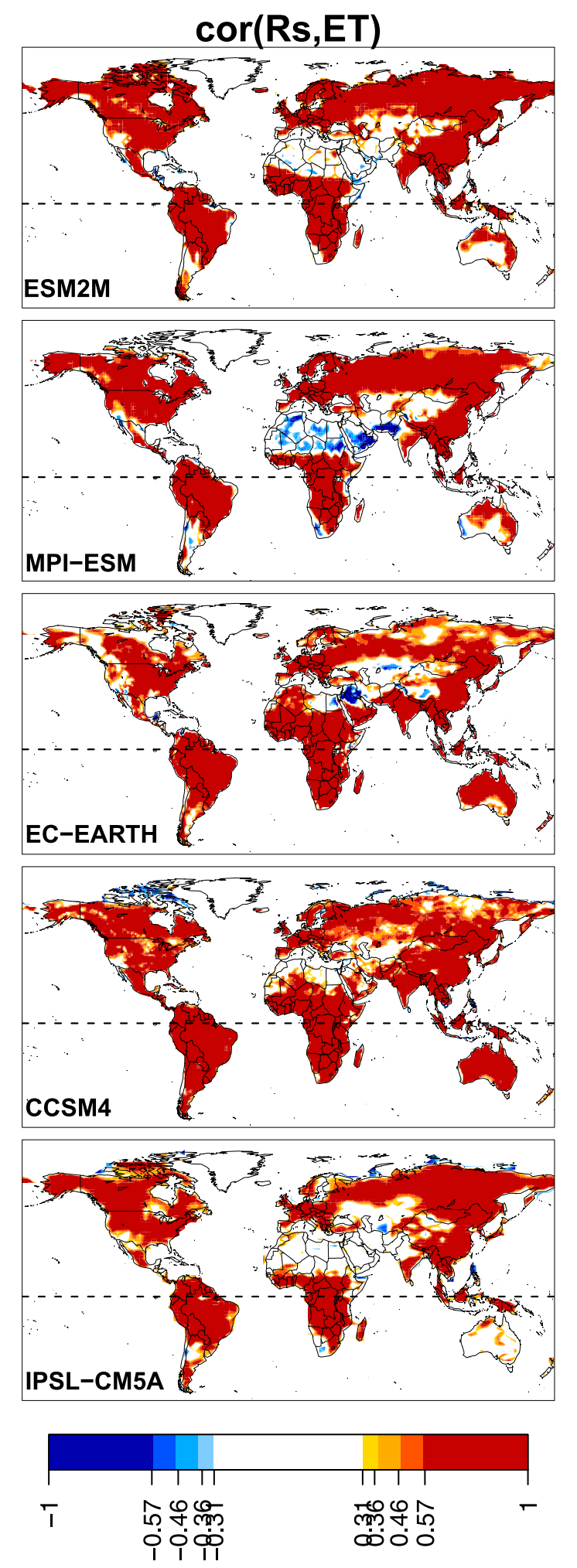

FIG. 6. Correlation between summertime-mean evapotranspiration and incoming shortwave radiation over 1971-2000 for the different models in expA. Color key corresponds to the $10 \%, 5 \%$, $1 \%$, and $0.1 \%$ levels of correlation significance. 
a) $\operatorname{cor}(\mathrm{Rs}, \mathrm{P})$

b) $\quad \operatorname{cor}(\mathrm{Rs}, \mathrm{T})$

c) $\quad \operatorname{cor}(\mathrm{T}, \mathrm{P})$
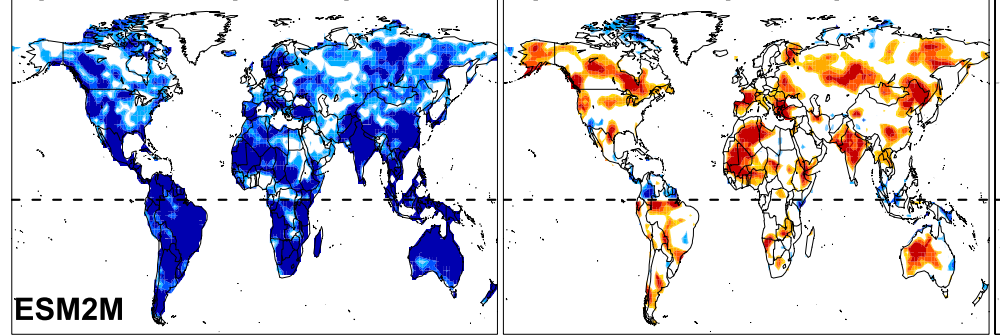

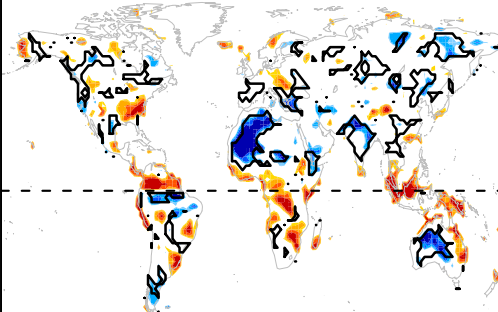
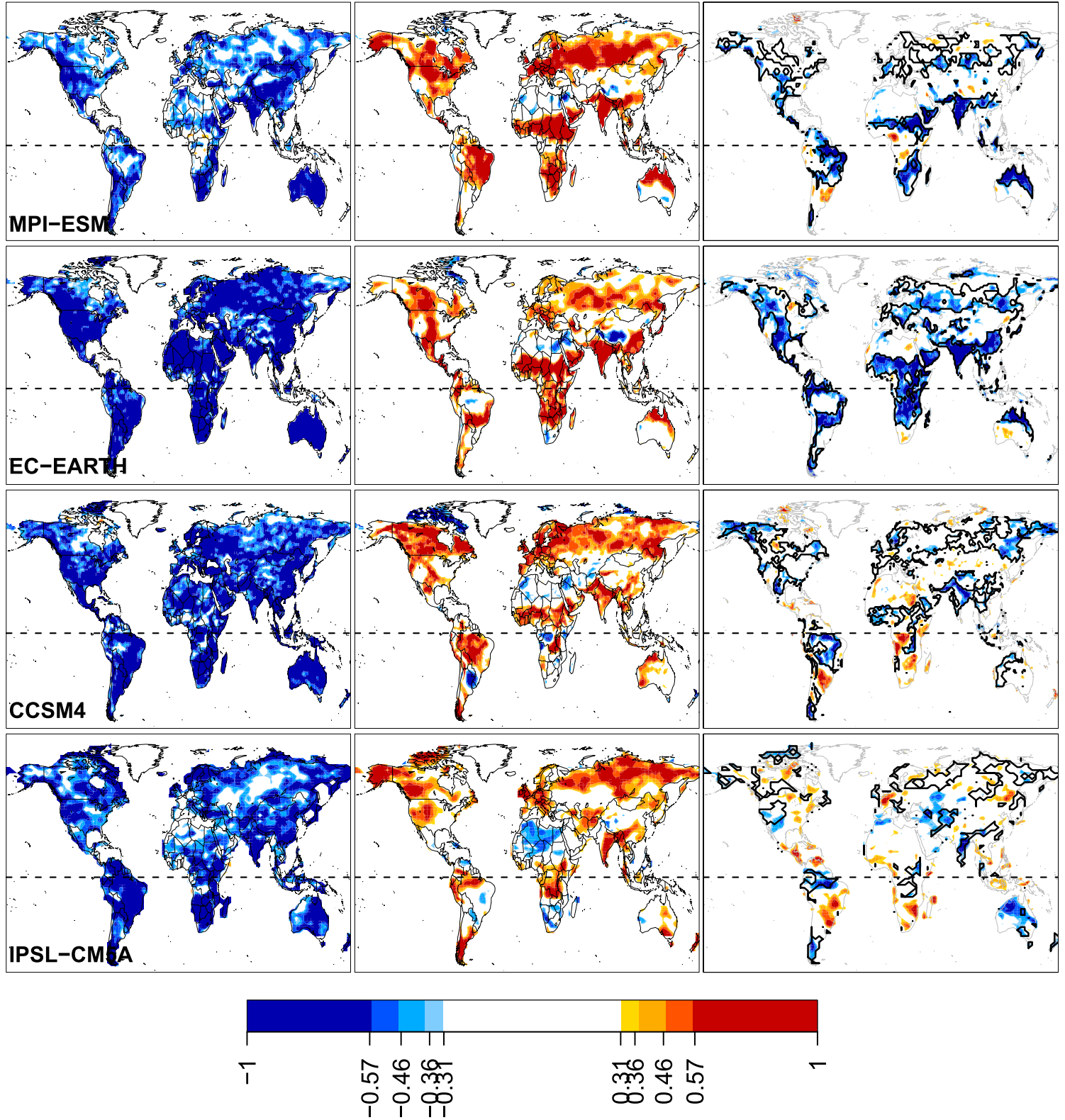

FIG. 7. Correlation in simulation expA between summertime-mean incoming shortwave radiation and (a) precipitation and (b) temperature over 1971-2000. (c) As in Fig. 3b, that is, $T-P$ correlations in simulation expA, with black contours indicating where the correlations between summertime-mean temperature and radiation [seen in (b)] are significantly positive whereas the correlations between summertimemean precipitation and radiation [seen in (a)] are significantly negative. Background land maps have been grayed (and interior borders were suppressed) in (c) to facilitate readability. Color key corresponds to the $10 \%, 5 \%, 1 \%$, and $0.1 \%$ levels of correlation significance. 
with solar radiation anomalies (Fig. 7a) and where, simultaneously, radiation anomalies are significantly (positively) correlated with surface temperature anomalies (Fig. 7b). Admittedly, this colocation is not proof of causation: we cannot rule out that a separate, different mechanism may independently generate such negative $T-P$ correlations in the models (in which case temperatureradiation and precipitation-radiation correlations of opposite sign may also independently be observed, as here). However, the good spatial match in Fig. 7c (particularly for MPI-ESM and EC-EARTH) and the physical plausibility of the underlying processes are suggestive of a direct radiative control on the $T-P$ correlation in $\operatorname{expA}$. Note that radiative terms other than solar radiation play no similar direct role in negative $T-P$ correlations. In particular, downwelling longwave radiation tends to be positively correlated with cloud cover and precipitation, so it would induce positive, instead of negative, $T-P$ correlations (since it heats the surface as well). This effect may actually act to oppose the impact of cloud cover and solar radiation on $T-P$ correlations: in particular, the lower negative $T-P$ correlations actually simulated by CCSM4 over large parts of Eurasia compared to the patterns of precipitationradiation-temperature covariations (black contours on Fig. 7c) correspond to regions where surface temperature appears more strongly associated with downwelling longwave radiation in CCSM4 than in other models (not shown). Thus, our interpretation is that in this model and this region, positive anomalies of cloud cover/precipitation are not clearly correlated with negative temperature anomalies, because of the effect of the associated longwave radiation on surface temperature.

As shown in Fig. 3b, negative $T-P$ correlations in expA are wider and more coherent in MPI-ESM and ECEARTH than in the other models. We interpret the differences between models as reflecting the differences between models in terms of cloud-radiative processes and impacts on the surface energy budget. Figure $7 \mathrm{a}$ shows that in simulation expA anomalies of precipitation across models are consistently and extensively associated with anomalies of incoming shortwave radiation of opposite signs. Differences between models mostly reflect different relationships between cloud cover and precipitation and, to a lesser extent, differences in the strength of the link between cloud cover and radiation (not shown). On the other hand, positive correlations between incoming shortwave radiation and temperature are less extensive; they also show more differences between models (Fig. 7b). These differences reflect the different sensitivities of surface temperature to incoming solar radiation in the models, in particular in a non-soil-moisturelimited evaporative regime such as in expA (see previous subsection). For EC-EARTH, MPI-ESM, and (to a lesser extent) CCSM4, these differences result in large swaths of positive correlations between summertimemean shortwave radiation and surface temperature in the tropics and high latitudes, whereas similar correlations are less extensive in ESM2M and IPSL-CM5A. As mentioned above, models also exhibit different relationships of surface temperature with downwelling longwave radiation (in particular CCSM4). The combination of these differences in longwave/shortwave radiationtemperature relationships with more minor differences in precipitation-radiation correlations explains the spread in $T-P$ correlations between models in expA (Fig. 3b). Overall, Figs. $7 \mathrm{a}$ and $7 \mathrm{~b}$ arguably reflect the aggregated effects of combined differences in parameterized cloud, convection, radiation, soil, and turbulence schemes between models.

\section{c. Land and atmospheric control on T-P correlations in $R E F$}

We now focus on the processes underlying $T-P$ correlations in the context of interactive soil moisture, in simulation REF.

Soil moisture-atmosphere interactions arguably contribute to negative interannual $T-P$ correlations in REF where correlation patterns in Fig. 3a overlap with regions of positive SM-ET correlation (soil moisture controlling ET) and negative ET- $T$ correlation (ET controlling temperature) in Fig. 5. To analyze this relationship, we combine information from Figs. 3 and 5 by binning $T-P$ correlations along SM-ET correlations and ET- $T$ correlations. Double histograms (or binned plots) on Fig. 8a thus show $T-P$ correlations in the different models in REF as a function of SM-ET and ET- $T$ correlations (over land). For each model, for a given bin of SM-ET and ET- $T$ correlation values, Fig. 8a displays the average $T-P$ correlation over all (map) pixels from Figs. $5 \mathrm{a}$ and $5 \mathrm{~b}$ that fall within this particular bin of SMET and ET $-T$ correlations; Fig. $8 \mathrm{~b}$ indicates the number of map pixels from Fig. 5 that fall in this bin. [To help interpret Fig. 8a in a spatial sense, Fig. S1 in the supplementary material displays the maps of pixels belonging to the different domains of the binned plots (i.e., the upper-left, upper-right, lower-right, and lower-left parts of the plots), showing the corresponding $T-P$ correlations.]

All models display negative $T-P$ correlations in the bottom-right part of the plots, which corresponds to the soil moisture-limited evaporative regime: this quadrant corresponds to regions where, as mentioned above, soil moisture controls evapotranspiration (positive SM-ET correlations) and evapotranspiration controls temperature (negative ET- $T$ correlations; see Fig. 5). The $T-P$ 


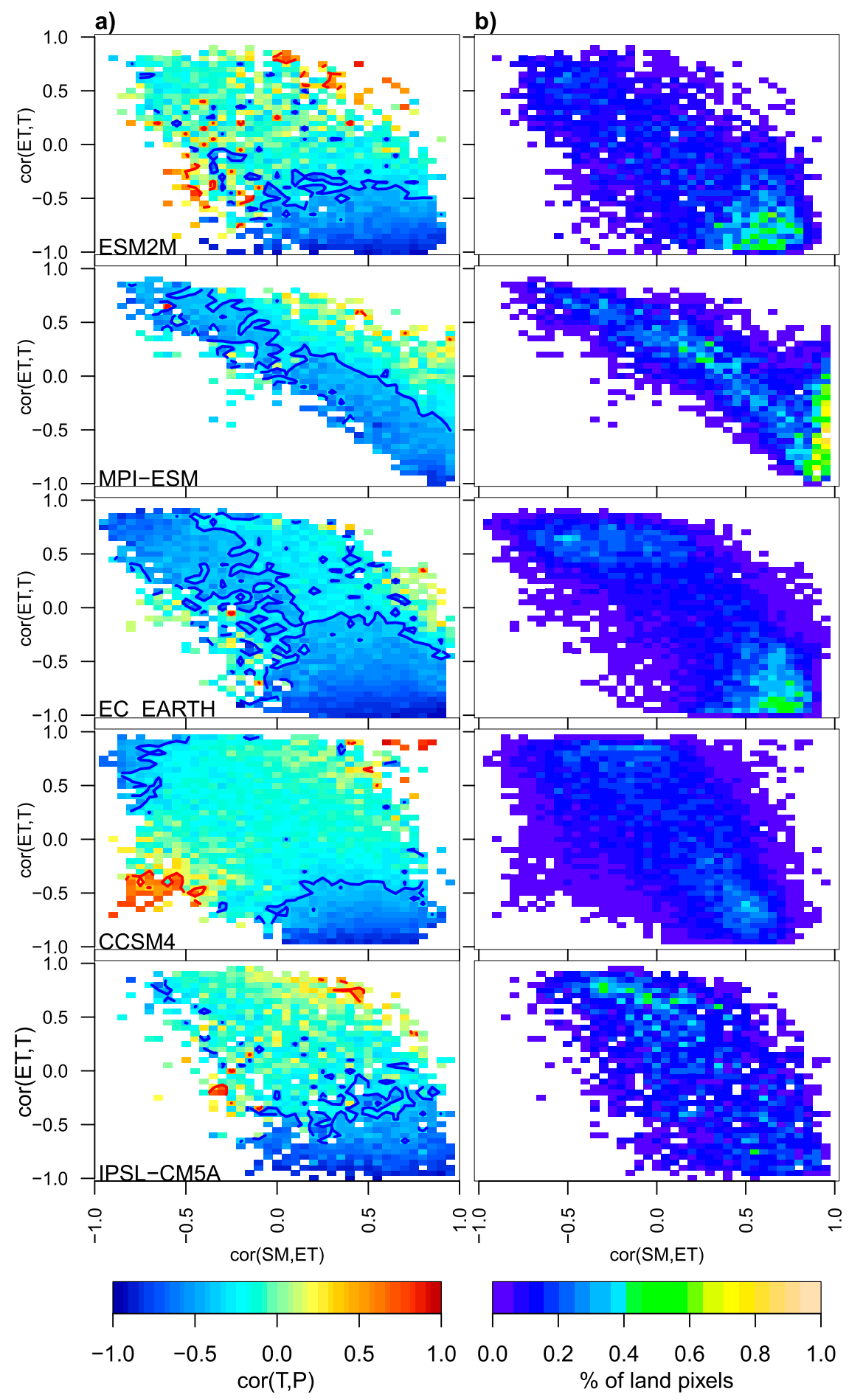

FIG. 8. (a) Correlation between summertime-mean temperature and precipitation in simulation REF binned as a function of correlations between soil moisture and evapotranspiration ( $x$ axis) and between evapotranspiration and temperature ( $y$ axis) for the different models over land over 1971-2000. Blue and red contours indicate negative and positive $T-P$ correlations, respectively, significant at the $5 \%$ level $(r=0.36)$. (b) Percentage of total number of land pixels in each model that fall in each bin. 
correlations are overwhelmingly negative in these regions (see also Fig. S1, far-right column). This indicates that in all models, soil moisture atmosphere interactions do contribute to negative $T-P$ correlations (in REF).

A benefit of the binned analysis is that it shows that some models also produce negative $T-P$ correlations in the upper-left part of the plots (EC-EARTH, MPIESM, and CCSM4 to a lesser extent). This domain corresponds to the energy-limited evaporative regime: in this quadrant, temperature drives evapotranspiration (positive ET- $T$ correlations) and evapotranspiration drives soil moisture (negative SM-ET correlation; see Fig. 5). [Figure S1 shows that, as mentioned in section 4a, these regions can be found at high latitudes and in the tropics (far-left column).] MPI-ESM displays negative $T-P$ correlations predominantly at high latitudes, while EC-EARTH does so mostly in the tropics (CCSM4 as well, but over the Amazon only). Since evapotranspiration in this regime is driven by atmospheric demand and drives soil moisture variability, negative $T-P$ correlations in this quadrant clearly do not result from precipitation's impact on soil moisture and soil moisture's subsequent control on evapotranspiration and temperature. Rather, we interpret them as resulting from the same atmospheric processes as highlighted in the previous section in simulation expA. This interpretation is supported by the consistency between Figs. 8a and 3b: the models that show negative $T-P$ correlations in the energy-limited evaporative regime in REF (upper-left part of the binned plots in Fig. 8a) are the same ones that display significant negative $T-P$ correlations in simulation expA in Fig. $3 b$ (EC-EARTH, MPI-ESM, and to a lesser extent CCSM4). In both cases, the surface evaporative regime is controlled by the atmosphere (see section $4 a$ ). Figures $3 b$ and 8 a thus provide two independent yet consistent lines of evidence that these models are capable of producing negative $T-P$ correlations that are not the product of soil moistureatmosphere interactions but rather emerge through atmospheric processes only.

Figure $8 \mathrm{~b}$ indicates that for most models, most (map) pixels (from Fig. 3a) lie in the bottom-right part of the binned plots: that is, there are more map pixels that fall into the soil moisture-limited evaporative regime; pixels in the energy-limited regime are comparatively less numerous (except for IPSL-CM5A; see also Fig. 5). More generally, Fig. $8 \mathrm{~b}$ shows that most pixels fall along a general bottom right-top left line. This is to be expected, as the two axes are not independent: a positive SM-ET correlation for instance, reflecting a soil moisture-limited evaporative regime, will tend to be associated with a negative ET- $T$ correlation (as more evapotranspiration will then cool the surface). However, Fig. 8a also shows hints of coherent positive $T-P$ correlation patterns emerging across models as one departs from this central line and moves toward the upper-right and lower-left quadrants, where SM-ET and ET- $T$ correlations follow different behaviors. These tend to correspond to pixels in, respectively, equatorial latitudes and high latitudes (Fig. S1). We note that these portions of the binned plots typically involve a small number of pixels (Fig. 8b), which are often dispersed, so limited sample size may be an issue. On the other hand, as indicated in section 3, coherent patches of positive $T-P$ correlations over equatorial latitudes exist in particular in equatorial Africa and the Maritime Continent in ESM2M and CCSM4; they correspond to the bottom-left quadrant in Fig. 8 (see also Fig. S1). The presence of positive correlations in both the interactive and prescribed soil moisture configurations (Fig. 3) indicates that these are decoupled from interactive soil moisture processes. Rather, we speculate that such correlations reflect simulated Clausius-Clapeyron temperature scaling of precipitable water, which in turn is tightly associated with local precipitation, similar to corresponding relationships over ocean surfaces (Neelin et al. 2009; Muller et al. 2009, 2011). As discussed in the introduction, there is some ambiguity in the significance of the observed correlations over equatorial latitudes (Fig. 1). In this context it is difficult to assess the validity or realism of the simulated regional covariability in the tropics. We note that the simulated tropical correlations are clearly model dependent, likely reflecting differences in parameterizations of clouds and convective precipitation between models in these regions.

Small coherent areas of positive $T-P$ correlations over high latitudes corresponding to the upper-right quadrant exist in particular in the IPSL-CM5A and CCSM4 models (Fig. S1); however, these positive correlations do not appear to be as significant or extensive as those in the tropics (see also Fig. 3a). The upper-right quadrant corresponds to mean hydroclimatic conditions under which summertime mean evapotranspiration appears to be, on average, controlled by both soil moisture (positive SM-ET correlation) and temperature (positive ET- $T$ correlation). One possible explanation for this model behavior is that precipitation over these areas is associated with advection of warmer, moister air: in this case, precipitation directly increases evapotranspiration (because of the positive SM-ET correlation), so the latter also appears associated with higher temperature.

\section{Implications for climate change}

In the previous section, we investigated the processes through which $T-P$ correlations at the interannual time scale (i.e., from one summer to the next) arise in the 


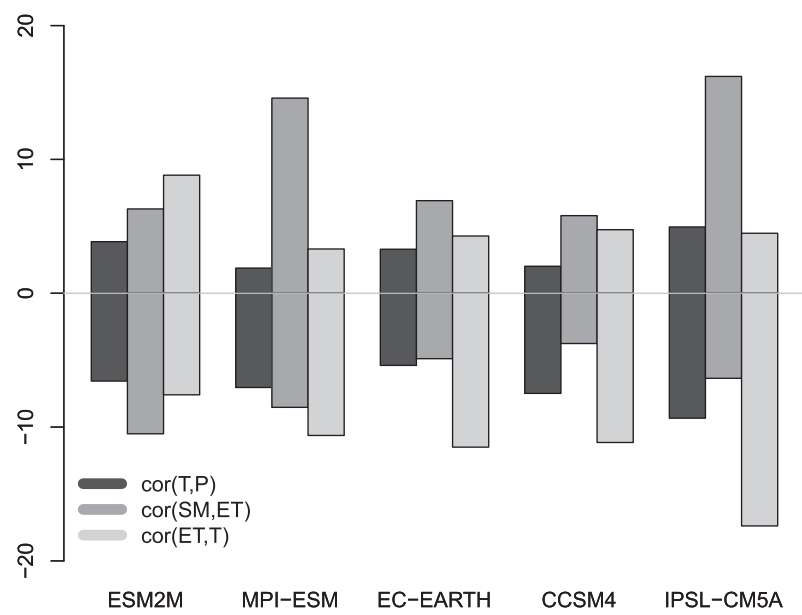

FIG. 9. Share of the land surface area (\%) where $T-P$, SM-ET, and ET $-T$ correlations become significantly more positive (positive bars) or significantly more negative (negative bars) between 19712000 and 2071-2100 (the difference being represented is future minus present) in different models in REF.

different climate models. Taking advantage of the fact that both simulations REF and expA were simulated through 2100 using the RCP8.5 scenario after 2005, we now focus on how $T-P$ correlations evolve in a warmer climate and what role they play in climate change projections.

\section{a. Projected future T-P correlations}

Figure 9 shows that in all models, parts of the land surface show significantly more negative $T-P$ correlations at the end of the twenty-first century (2071-2100) compared to the end of the twentieth century (19712000), while correlations also become significantly more positive in other areas (note that areas becoming more positive may still correspond to negative correlations). In MPI-ESM, CCSM4, and IPSL-CM5A, areas where correlations become significantly more negative clearly outweigh areas where significant positive changes occur, which reflects an increase in the total area of significant negative $T-P$ correlations. Similar changes are less evident for ESM2M and EC-EARTH. Despite these changes, the overall spatial pattern of $T-P$ correlations (Fig. 3a) remains similar in the future in the different models (not shown). We note here that we cannot assess the field significance of these changes in $T-P$ correlations between present and future through the same Monte Carlo approach as used in Figs. 1 and 3, as it would require sampling a control simulation with no changes in climate forcing agents. We point out that the net change (i.e., the area difference between areas becoming significantly more negative and areas becoming significantly more positive) remains smaller than $6 \%$ of the land surface in all models.
Because in all models negative $T-P$ correlations arise either partly or mostly as a result of soil moisture's feedbacks on surface temperature (see previous section), we analyze concurrent changes in SM-ET and ET- $T$ correlations. Figure 9 shows that in MPI-ESM, CCSM4, and IPSL-CM5A, significant changes in SM-ET and ET $-T$ correlations are, respectively, predominantly positive and negative, reflecting an increased control of soil moisture on evapotranspiration and increased control of evapotranspiration on temperature. (Figure S2 in the supplementary material illustrates these changes spatially and shows that concurrent changes in SM-ET and ET-T mainly occur at high northern latitudes.) This shift toward soil moisture-controlled conditions in summer in the future in regions such as eastern/northern Europe and Siberia is consistent with previous modeling results (Seneviratne et al. 2006; Dirmeyer et al. 2012, 2013). This strengthening of the land-atmosphere pathway (Fig. 2) is consistent with the more negative $T-P$ correlations in these models; one must note, however, that areas of more negative $T-P$ correlations do not necessarily overlap with areas of increased soil moisture control (e.g., central Asia in MPI-ESM). In ESM2M, no such strengthening of the land-atmosphere pathway can be seen; rather, it seems that soil moisture's control on evapotranspiration becomes less pronounced in the future (Figs. 9 and S2). In EC-EARTH, a small shift toward more soil moisture-controlled conditions is projected over eastern Europe, which appears to result in stronger negative $T-P$ correlations over this region.

\section{b. Regional temperature change}

We now investigate whether $T-P$ covariability at the interannual time scale, such as diagnosed by $T-P$ correlations, affects long-term temperature change over land in the models. Because patterns of $T-P$ correlations show overall modest change in the future in the models (or become even more negative; see previous subsection), we use present-climate $T-P$ correlations to investigate how projected future warming is affected by interannual $T-P$ covariability in the models. We do so using a binned grid cell framework similar to Fig. 8.

First, Fig. 10a shows the mean summertime warming projected between 1971-2000 and 2071-2100 in the different models in simulation REF. Differences in the average temperature change reflect differences in climate sensitivities: IPSL-CM5A shows the largest overall warming, while ESM2M shows the smallest (with even some cooling in the Southern Ocean and the North Atlantic). In all models, summertime warming is greater over land than over the oceans, consistent with a land-sea warming ratio greater than unity (e.g., Sutton et al. 2007); however, patterns of changes over land differ between models. 
a)
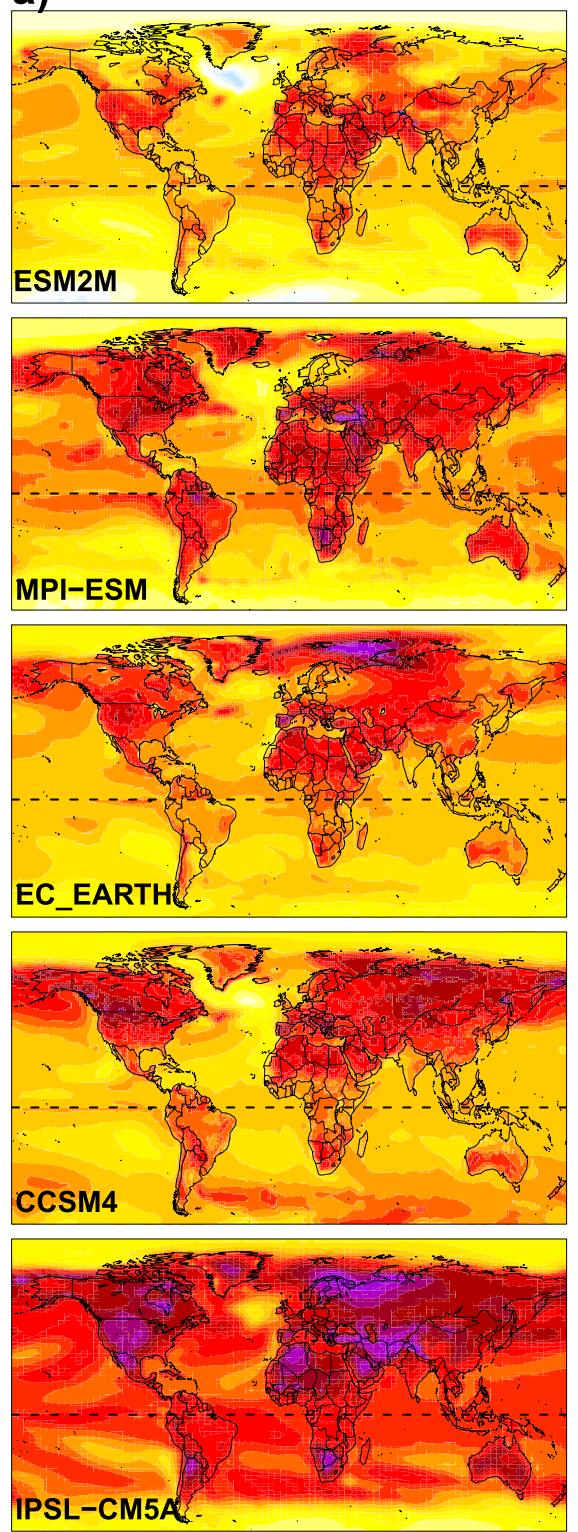

IPSL-CM5A
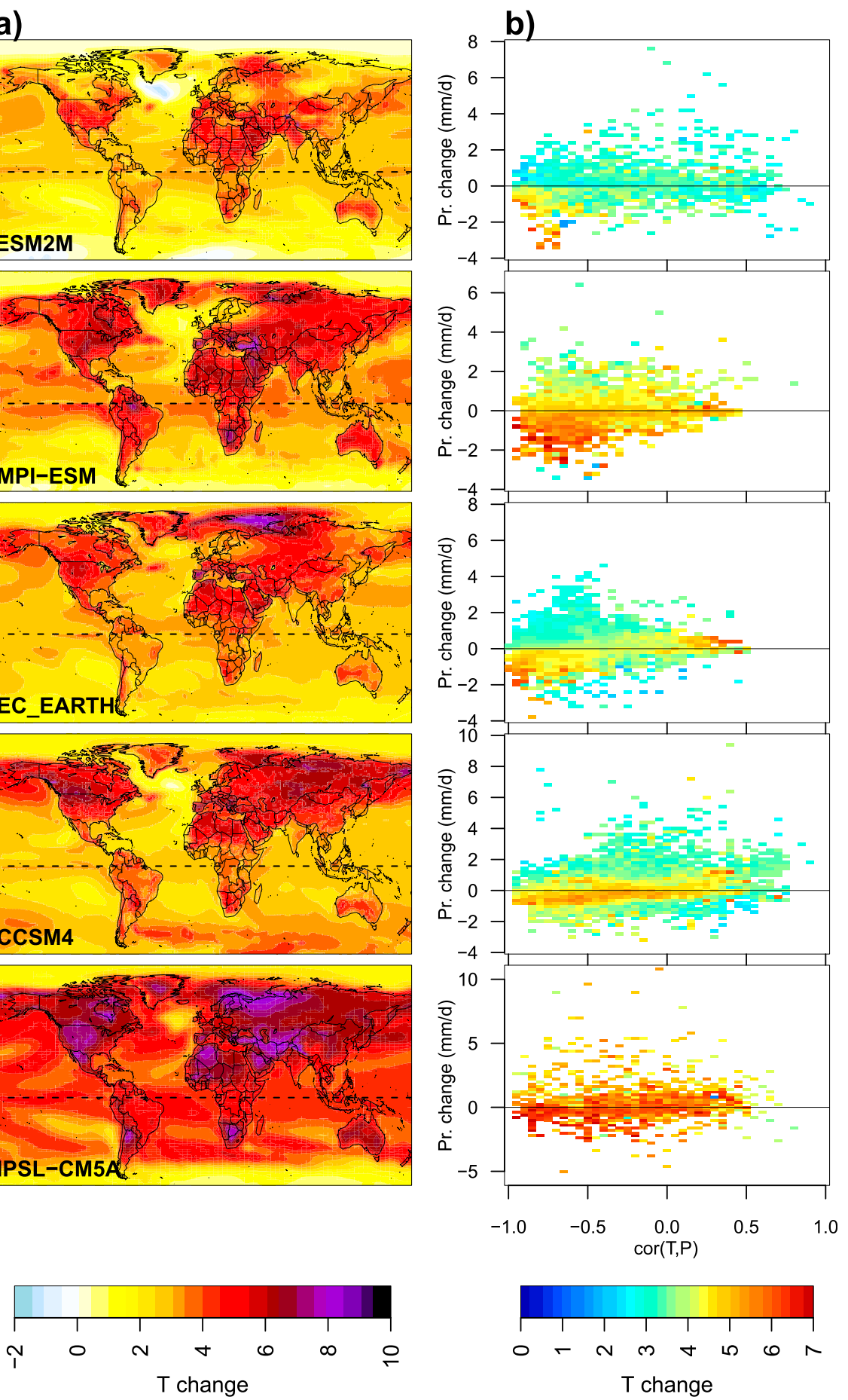

FIG. 10. (a) Mean summer $T$ change (K) between 1971-2000 and 2071-2100 in simulation REF. (b) Mean summer $T$ change between 1971-2000 and 2071-2100 from (a) (color; K) binned along correlations between present time (1971-2000) summertime-mean $T$ and $P$ ( $x$ axis) and mean summertime $P$ change between 1971-2000 and 2071-2100 ( $y$ axis; $\left.\mathrm{mm} \mathrm{day}^{-1}\right)$, pixels over land only. 
Figure 10b helps shed light on these differences by showing that the land regions of maximum warming in the models tend to correspond to regions that exhibit both the highest $T-P$ summertime anticorrelations in current climate and negative projected precipitation changes. This pattern is particularly clear in ESM2M, MPI-ESM, and EC-EARTH and somewhat less pronounced in CCSM4 and IPSL-CM5A. A few pixels of maximum warming also appear in regions of positive $T-P$ correlations in Fig. 10b (in general with positive precipitation change) corresponding to large warming in desert areas (see Fig. 3a). In some models (ESM2M and MPI-ESM), conversely, minimum long-term warming is projected in regions that exhibit both the highest $T-P$ summertime anticorrelations in current climate and positive projected precipitation changes.

This indicates that, consistently across models, $T-P$ correlations have the potential to modulate long-term warming in conjunction with precipitation change. This is consistent with prior studies (Madden and Williams 1978; Déry and Wood 2005) showing that the $T-P$ relationship holds over a range of time scales, including decadal variability and secular trends.

Figure 11a shows that in the absence of soil moisture change, long-term warming is largely reduced over land in expA compared to REF. This is consistent with the role of average soil moisture change (between present and future) in amplifying summertime warming over land, as shown in Seneviratne et al. (2013). This difference highlights the role of land-atmosphere interactions in the land-sea warming contrast projected by climate models (Sutton et al. 2007). Figure 11b shows that in contrast to REF, no relationship similar to that in Fig. 10b emerges between long-term warming, precipitation change and $T-P$ correlations in simulation expA-with the exception of MPI-ESM. Interestingly, while EC-EARTH and MPIESM both display the most negative $T-P$ correlations in expA over 1971-2000 (both in extent and intensity; Fig. 4), they show different behaviors in terms of long-term warming (in expA): EC-EARTH does not exhibit a relationship between future warming and $T-P$ correlations in this simulation, whereas MPI-ESM does. It thus appears unclear whether processes associated with the atmospheric pathway (Fig. 2), which result in negative $T-P$ correlations at the interannual time scale, can also affect future surface warming through concurrent long-term changes in precipitation. At the very least, comparison between Figs. 10b and 11b suggests that land-atmosphere interactions contribute to the warming patterns in Fig. 10b to a large extent. In other words, our results indicate that through soil moisture feedbacks on near-surface climate, regional trends in precipitation may strongly modulate regional temperature change from global warming.

\section{Discussion}

By comparing an ensemble of simulations with and without interactive soil moisture, we investigated the mechanisms responsible for negative $T-P$ correlations for the first time in a suite of climate models. We have demonstrated that negative correlations between summertimemean temperature and precipitation can arise through two mechanistic pathways in climate models, as described in Fig. 2. The across-the-board decrease in $T-P$ correlations between REF and expA in Figs. $3 a$ and $3 b$ indicates that the terrestrial pathway (i.e., the control of soil moisture on surface heat fluxes and temperature) largely contributes to these correlations in all models. However, while soil moisture-atmosphere interactions are the main driver in some models, in others (mainly, MPIESM and EC-EARTH) these correlations also emerge in the absence of soil moisture-atmosphere coupling (expA). Our analysis indicates that this comes in response to the stronger association in these models between cloud cover and precipitation on the one hand, and between solar radiation and surface temperature on the other hand. Consistently, Fig. 8 shows that in the context of interactive soil moisture (REF), these models are capable of producing negative $T-P$ correlations, not only in soil moisture-limited regions, but also in regions of energy-limited evaporative regime, where soil moisture variability does not feed back on surface temperature. This suggests that, in these models, the atmospheric pathway may also contribute to negative $T-P$ correlations even in soil moisture-limited regions: in such regions, surface temperature may also be partly driven by the radiation anomalies associated with precipitation and soil moisture variability. This hypothesis is supported by the fact that in MPI-ESM and EC-EARTH, areas with atmosphere-driven negative $T-P$ correlations in expA (Fig. 3b) are found in the same regions that display landdriven correlations in REF (this is also the case in the other models over regions such as Australia or India). This suggests that atmospheric processes associating $T$ and $P$ (isolated in simulation expA) also contribute to the negative correlations in these regions in REF in Fig. 2a. This is also consistent with the result that EC-EARTH, which shows the most extensive and strongest correlations in REF, also displays the strongest negative correlations in expA. In other words, in these models the two pathways appear to act in combination to produce strong negative $T-P$ correlations over these regions. This additivity suggests that the contribution of soil moisture-atmosphere interactions to negative $T-P$ correlations can be inferred from the difference between simulations REF and expA in Fig. 4. Interestingly, some regions show positive $T-P$ correlations in the absence of soil moisture-atmosphere 
a)
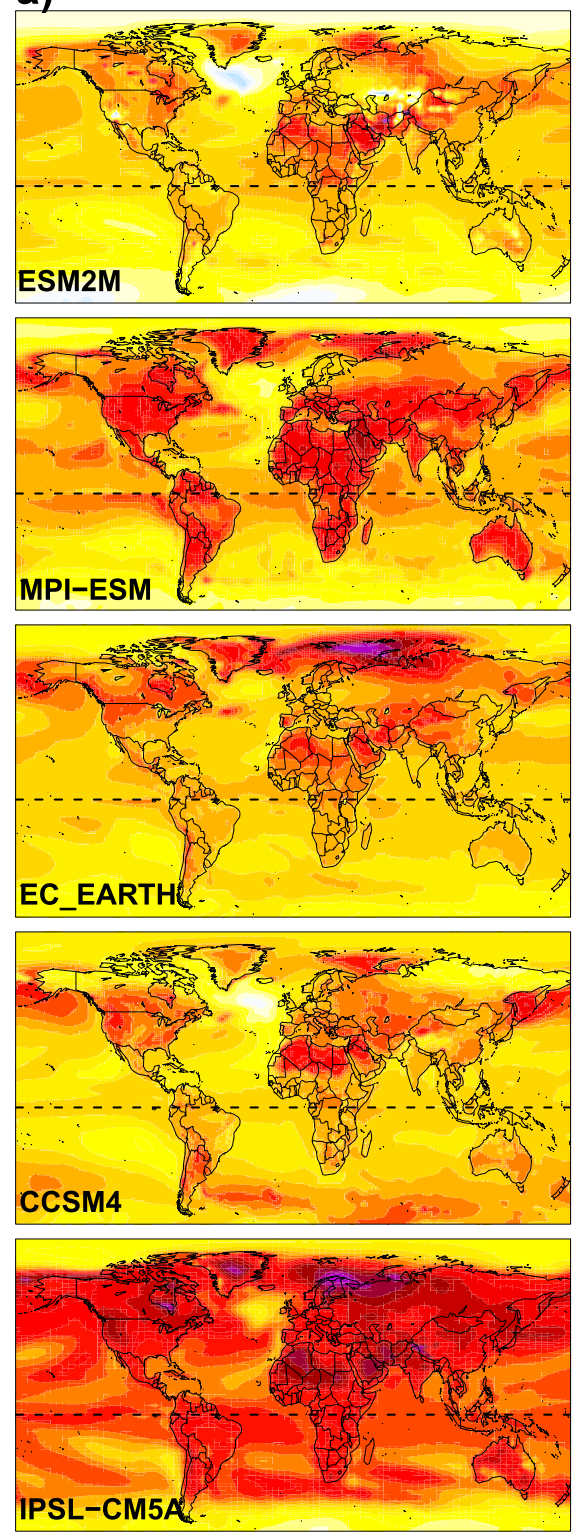

IPSL-CM5A.
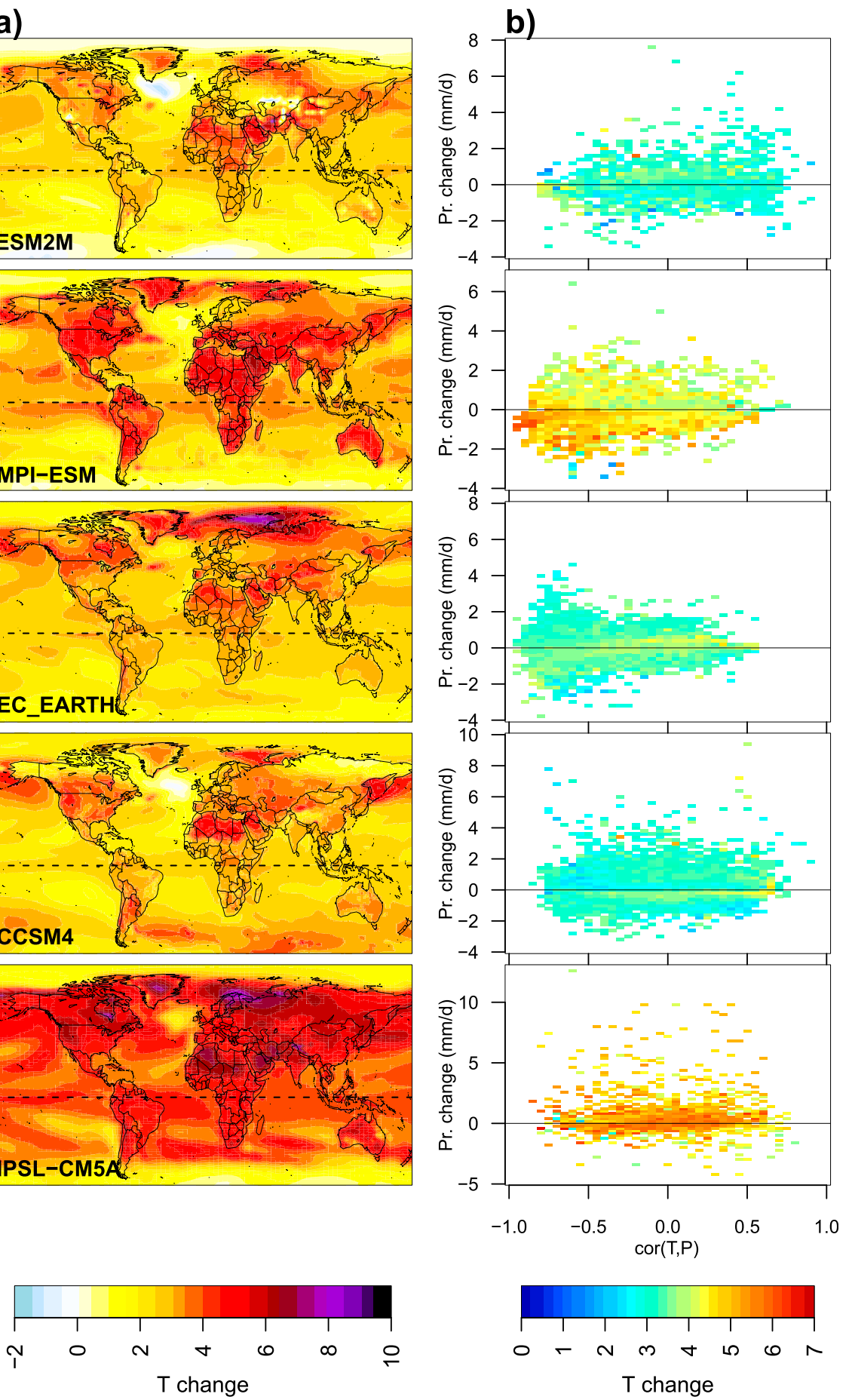

FIG. 11. As in Fig. 10, but for expA simulation. Note that temperature changes over the oceans in (a) are the same as in Fig. 10 for simulation REF, since similar sea surface temperatures were prescribed in both experiments.

interactions and negative $T-P$ correlations otherwise (Fig. 3). This suggests that in some cases these interactions can act to oppose the atmospheric regime: these regions appear to be mostly located on the eastern side of continents (in the Southern Hemisphere), under the influence of air masses from the ocean; while this would result in positive $T-P$ correlations if only the atmosphere was driving $T-P$ covariability (as suggested by 
Fig. 3b), the water-limited evaporative regime in these regions (Fig. 5) reverses the relationship between $T$ and $P$ on average over the summer.

In this analysis one should be reminded that the soil moisture-atmosphere interactions pathway defined in Fig. 2 also inherently includes the feedback of modified surface turbulent heat fluxes on cloud cover and radiation. For instance, in the case of a negative precipitation anomaly and subsequent soil moisture deficit, reduced evapotranspiration (which directly leads to higher surface temperature) may also negatively impact cloud cover and thus enhance incoming shortwave radiation, thereby further enhancing surface warming (Betts 2004; Ferranti and Viterbo 2006; Davin et al. 2011; Gentine et al. 2013); it may even further reduce precipitation (e.g., Berg et al. 2013). The GLACE-CMIP5 experimental setup does not allow for separating these feedbacks from the direct impact of soil moisture on the surface energy budget and temperature. We note that some models (ESM2M) show increased interannual variability of mean summertime cloud cover between simulations REF and expA over some regions of negative $T-P$ correlations, which suggests that feedbacks of surface fluxes to cloud cover are at play over these regions; however, most models do not show such changes.

Overall, our analysis points to important uncertainties emerging at the seasonal-mean, interannual time scale between climate models with respect to various functional relationships, such as the control of soil moisture on evapotranspiration, the relationship of cloud cover with radiation and precipitation, or the impact of surface radiation on temperature. These differences are not unexpected, given that these emerging relationships are the result of small-scale parameterization schemes, such as cloud, convection, radiation, soil hydrology, and boundary layer schemes. Through the interplay between these components, differences from the details of these parameterizations grow and result in different behaviors at larger and longer spatiotemporal scales. Consistent with our analysis, previous studies have noted, for instance, that climate models exhibit different apparent sensitivities of surface temperature variability to processes such as evapotranspiration and solar radiation (Lenderink et al. 2007; Fischer and Schar 2009). Such uncertainties ultimately undermine our ability to use these models to analyze observed climate phenomena such as $T-P$ covariability: here, our multimodel analysis shows that model uncertainties hinder a clear and quantitative understanding and attribution of observed $T-P$ correlations to particular processes, such as landatmosphere interactions or cloud-radiative processes. There is thus a need to better evaluate process-level, multivariate relationships in climate models. We note, however, that while $T-P$ correlations can readily be derived from observations, more uncertainties and limitations affect observations of the relevant underlying variables and their relationships at similar global and interannual scales (e.g., soil moisture, surface fluxes, and radiation). It is thus difficult to constrain climate models regarding these processes. We note that recent studies indicate that climate models in CMIP5 tend to be too warm in summer over land (Christensen and Boberg 2012; Mueller and Seneviratne 2014). While the comprehensive causes of such biases are a subject of current investigation and may involve numerous physical processes (e.g., Ma et al. 2014), one possibility is that they overestimate summertime drying, and thus the subsequent feedback on surface temperature (Stegehuis et al. 2013). Locked in a dry and warm soil moisturelimited regime, models may then overestimate soil moisture-atmosphere interactions (Christensen and Boberg 2012). In contrast, some recent observational studies emphasize the role of cloud cover in the variance of summer temperature (Tang et al. 2012; Tang and Leng 2013). It is thus possible that models overestimate the contribution of soil moisture-atmosphere interactions to the negative $T-P$ correlations investigated in this study. Future improvements in global land-atmosphere observational datasets, as well as pointwise land-atmosphere model evaluation exercises, may help further constrain such model uncertainties.

\section{Conclusions}

Widespread negative correlations between summertimemean temperatures and precipitation have long been observed over land. Using simulations from the GLACECMIP5 multimodel experiment with and without interactive soil moisture, we explored for the first time the mechanisms responsible for such $T-P$ covariability at the interannual time scale in a suite of climate models. Our results generally confirm the interpretation of such correlations arising largely through the direct control of soil moisture on surface heat flux partitioning: in all models soil moisture-atmosphere interactions contribute largely to these correlations. However, in some models the association of cloud cover with precipitation on the one hand, and of solar radiation with surface temperature on the other hand, appears sufficient to generate significant negative correlations between temperature and precipitation, without feedbacks from the land surface. This range of model behavior suggests that observed temperature-precipitation anticorrelations may result from a combination of atmospheric and surface processes. Our results also underline the uncertainties between models regarding cloud-radiative processes and their link to surface temperature. Finally, we 
showed that on longer time scales, the negative correlation between precipitation and temperature over land has implications for the projection of climate change impacts on near-surface climate: in all models, in regions of strong temperature-precipitation coupling, long-term regional warming is modulated to a large extent by projected precipitation changes. In most models this appears to be the result of soil moisture-atmosphere interactions. An important issue in climate sciences is the response of the global hydrologic cycle to global warming, in particular possible changes in precipitation patterns and amounts (e.g., Wentz et al. 2007). Our results demonstrate how regional-scale modifications to the water cycle can feed back on surface temperature changes through soil moisture control on evapotranspiration. These results imply that uncertainties in regional precipitation change, which are a well-documented issue of climate model projections, in particular in the tropics (e.g., Neelin et al. 2006; Knutti and Sedláček 2012), directly translate into uncertainties in temperature change. This arguably has compounding effects on uncertainties associated with climate change impacts on natural and human systems, but also suggests that reducing uncertainties in precipitation projections will help reduce the uncertainties in projected regional temperature change. This also implies that the correct representation of land surface hydrological processes in climate models is a key element to providing improved and more robust regional projections of global climate change.

Acknowledgments. Alexis Berg was supported by National Science Foundation (NSF) Grants AGS-1035968 and AGS-1035843 and New Jersey Agricultural Experiment Station Hatch Grant NJ07102, and is currently supported by NSF Postdoctoral Fellowship AGS-1331375. S.I.S. acknowledges support of the EU-FP7 EMBRACE project (European Commission's 7th Framework Programme, Grant Agreement 282672), and the GEWEX (World Climate Research Programme, WCRP) and ILEAPS (Integrated Geosphere-Biosphere Programme, IGBP) projects, for the coordination and realization of the GLACE-CMIP5 experiment. S.M. acknowledges support from the National Oceanic and Atmospheric (U.S. Department of Commerce) Grant NA08OAR4320752, U.S. Department of Agriculture Grant 2011-67003-30373, and the Carbon Mitigation Initiative at Princeton University, sponsored by British Petroleum. The University of Delaware, CMAP, and GPCP datasets are provided by the NOAA/OAR/ ESRL PSD, Boulder, Colorado, from their website at http://www.esrl.noaa.gov/psd/. We thank Micah Wilhelm for his help with the GLACE-CMIP5 multimodel database.

\section{REFERENCES}

Adler, R. F., G. J. Gu, J. J. Wang, G. J. Huffman, S. Curtis, and D. Bolvin, 2008: Relationships between global precipitation and surface temperature on interannual and longer timescales (1979-2006). J. Geophys. Res., 113, D22104, doi:10.1029/ 2008JD010536.

Berg, A., K. Findell, B. Lintner, P. Gentine, and C. Kerr, 2013: Precipitation sensitivity to surface heat fluxes over North America in reanalysis and model data. J. Hydrometeor., 14, 722-743, doi:10.1175/JHM-D-12-0111.1.

Betts, A. K., 2004: Understanding hydrometeorology using global models. Bull. Amer. Meteor. Soc., 85, 1673-1688, doi:10.1175/ BAMS-85-11-1673.

Christensen, J. H., and F. Boberg, 2012: Temperature dependent climate projection deficiencies in CMIP5 models. Geophys. Res. Lett., 39, L24705, doi:10.1029/2012GL053650.

Davin, E. L., R. Stöckli, E. B. Jaeger, S. Levis, and S. I. Seneviratne, 2011: COSMO-CLM ${ }^{2}$ : A new version of the COSMO-CLM model coupled to the Community Land Model. Climate Dyn., 37, 1889-1907, doi:10.1007/s00382-011-1019-z.

Déry, S. J., and E. F. Wood, 2005: Observed twentieth century land surface air temperature and precipitation covariability. Geophys. Res. Lett., 32, L21414, doi:10.1029/2005GL024234.

Dirmeyer, P. A., 2011: The terrestrial segment of soil moistureclimate coupling. Geophys. Res. Lett., 38, L16702, doi:10.1029/ 2011GL048268.

—_, and Coauthors, 2012: Evidence for enhanced landatmosphere feedback in a warming climate. J. Hydrometeor., 13, 981-995, doi:10.1175/JHM-D-11-0104.1.

—, Y. Jin, B. Singh, and X. Yan, 2013: Trends in landatmosphere interactions from CMIP5 simulations. J. Hydrometeor., 14, 829-849, doi:10.1175/JHM-D-12-0107.1.

Durre, I., J. M. Wallace, and D. P. Lettenmaier, 2000: Dependence of extreme daily maximum temperatures on antecedent soil moisture in the contiguous United States during summer. J. Climate, 13, 2641-2651, doi:10.1175/1520-0442(2000)013<2641: DOEDMT $>2.0 . \mathrm{CO} ; 2$.

Entekhabi, D., I. Rodriguez-Iturbe, and R. L. Bras, 1992: Variability in large-scale water-balance with land surfaceatmosphere interaction. J. Climate, 5, 798-813, doi:10.1175/ 1520-0442(1992)005<0798:VILSWB > 2.0.CO;2.

Ferranti, L., and P. Viterbo, 2006: Sensitivity to soil water initial conditions. J. Climate, 19, 3659-3680, doi:10.1175/JCLI3810.1.

Fischer, E. M., and C. Schar, 2009: Future changes in daily summer temperature variability: Driving processes and role for temperature extremes. Climate Dyn., 33, 917-935, doi:10.1007/ s00382-008-0473-8.

— S. I. Seneviratne, D. Luthi, and C. Schär, 2007: Contribution of land-atmosphere coupling to recent European summer heat waves. Geophys. Res. Lett., 34, L06707, doi:10.1029/ 2006 GL029068.

Gentine, P., A. A. Holtslag, F. D'Andrea, and M. Ek, 2013: Surface and atmospheric controls on the onset of moist convection over land. J. Hydrometeor., 14, 1443-1462, doi:10.1175/ JHM-D-12-0137.1.

Guo, Z., and Coauthors, 2006: GLACE: The Global LandAtmosphere Coupling Experiment. Part II: Analysis. J. Hydrometeor., 7, 611-625, doi:10.1175/JHM511.1.

Haarsma, R. J., F. Selten, B. van den Huk, W. Hazeleger, and X. L. Wang, 2009: Drier Mediterranean soils due to greenhouse warming bring easterly winds over summertime central Europe. Geophys. Res. Lett., 36, L04705, doi:10.1029/2008GL036617. 
Hirschi, M., and Coauthors, 2011: Observational evidence for soilmoisture impact on hot extremes in southeastern Europe. Nat. Geosci., 4, 17-21, doi:10.1038/ngeo1032.

Jung, M., and Coauthors, 2010: Recent decline in the global land evapotranspiration trend due to limited moisture supply. $\mathrm{Na}$ ture, 467, 951-954, doi:10.1038/nature09396.

Knutti, R., and J. Sedláček, 2012: Robustness and uncertainties in the new CMIP5 climate model projections. Nat. Climate Change, 3, 369-373, doi:10.1038/nclimate1716.

Koster, R. D., and Coauthors, 2004: Regions of strong coupling between soil moisture and precipitation. Science, 305, 11381140, doi:10.1126/science.1100217.

- , and Coauthors, 2006: GLACE: The Global LandAtmosphere Coupling Experiment. Part I: Overview. J. Hydrometeor., 7, 590-610, doi:10.1175/JHM510.1.

— , Z. Guo, R. Yang, P. A. Dirmeyer, K. Mitchell, and M. J. Puma, 2009a: On the nature of soil moisture in land surface models. J. Climate, 22, 4322-4335, doi:10.1175/2009JCLI2832.1.

- S. D. Schubert, and M. J. Suarez, 2009b: Analyzing the concurrence of meteorological droughts and warm periods, with implications for the determination of evaporative regime. J. Climate, 22, 3331-3341, doi:10.1175/ 2008JCLI2718.1.

— and Coauthors, 2010: Contribution of land initialization to subseasonal forecast skill: First results from a multi-model experiment. Geophys. Res. Lett., 37, L02402, doi:10.1029/ 2009 GL041677.

Krakauer, N., B. Cook, and M. Puma, 2010: Contribution of soil moisture feedback to hydroclimatic variability. Hydrol. Earth Syst. Sci., 14, 505-520, doi:10.5194/hess-14-505-2010.

Lenderink, G., A. van Ulden, B. van den Hurk, and E. van Meijgaard, 2007: Summertime inter-annual temperature variability in an ensemble of regional model simulations: Analysis of the surface energy budget. Climatic Change, 81, 233-247, doi:10.1007/ s10584-006-9229-9.

Livezey, R. E., and W. Y. Chen, 1983: Statistical field significance and its determination by Monte Carlo techniques. Mon. Wea. Rev., 111, 46-59, doi:10.1175/1520-0493(1983)111<0046: SFSAID $>2.0 . \mathrm{CO} ; 2$.

Ma, H.-Y., and Coauthors, 2014: On the correspondence between mean forecast errors and climate errors in CMIP5 models. J. Climate, 27, 1781-1798, doi:10.1175/JCLI-D-13-00474.1.

Madden, R. A., and J. Williams, 1978: The correlation between temperature and precipitation in the United States and Europe. Mon. Wea. Rev., 106, 142-147, doi:10.1175/ 1520-0493(1978)106<0142:TCBTAP $>2.0$. CO;2.

Miralles, D. G., M. J. van den Berg, A. J. Teuling, and R. A. M. de Jeu, 2012: Soil moisture-temperature coupling: A multiscale observational analysis. Geophys. Res. Lett., 39, L21707, doi:10.1029/2012GL053703.

Mueller, B., and S. I. Seneviratne, 2012: Hot days induced by precipitation deficits at the global scale. Proc. Natl. Acad. Sci. USA, 109, 12 398-12 403, doi:10.1073/pnas.1204330109.

— and - 2014: Systematic land climate and evapotranspiration biases in CMIP5 simulations. Geophys. Res. Lett., 41, 128-134, doi:10.1002/2013GL058055.

Muller, C. J., L. E. Back, P. A. O'Gorman, and K. E. Emanuel, 2009: A model for the relationship between tropical precipitation and column water vapor. Geophys. Res. Lett., 36, L16804, doi:10.1029/2009GL039667.

_ , P. A. O'Gorman, and L. E. Back, 2011: Intensification of precipitation extremes with warming in a cloud-resolving model. J. Climate, 24, 2784-2800, doi:10.1175/2011JCLI3876.1.
Neelin, J. D., M. Münnich, H. Su, J. E. Meyerson, and C. E. Holloway, 2006: Tropical drying trends in global warming models and observations. Proc. Natl. Acad. Sci. USA, 103, 6110-6115, doi:10.1073/pnas.0601798103.

, O. Peters, and K. Hales, 2009: The transition to strong convection. J. Atmos. Sci., 66, 2367-2384, doi:10.1175/2009JAS2962.1.

Portmann, R. W., S. Solomon, and G. C. Hegerl, 2009: Spatial and seasonal patterns in climate change, temperatures, and precipitation across the United States. Proc. Natl. Acad. Sci. USA, 106, 7324-7329, doi:10.1073/pnas.0808533106.

Quesada, B., R. Vautard, P. Yiou, M. Hirschi, and S. I. Seneviratne, 2012: Asymmetric European summer heat predictability from wet and dry southern winters and springs. Nat. Climate Change, 2, 736-741, doi:10.1038/nclimate1536.

R Core Team, 2012: R: A language and environment for statistical computing. R Foundation for Statistical Computing. [Available online at http://www.R-project.org/.]

Rebetez, M., 1996: Seasonal relationship between temperature, precipitation and snow cover in a mountainous region. Theor. Appl. Climatol., 54, 99-106, doi:10.1007/BF00865152.

Rusticucci, M., and O. Penalba, 2000: Interdecadal changes in the precipitation seasonal cycle over southern South America and their relationship with surface temperature. Climate Res., 16, 1-15, doi:10.3354/cr016001.

Seneviratne, S. I., D. Lüthi, M. Litschi, and C. Schär, 2006: Landatmosphere coupling and climate change in Europe. Nature, 443, 205-209, doi:10.1038/nature05095.

T. Corti, E. L. Davin, M. Hirschi, E. B. Jaeger, I. Lehner, B. Orlowsky, and A. J. Teuling, 2010: Investigating soil moistureclimate interactions in a changing climate: A review. Earth-Sci. Rev., 99, 125-161, doi:10.1016/j.earscirev.2010.02.004.

, and Coauthors, 2013: Impact of soil moisture-climate feedbacks on CMIP5 projections: First results from the GLACECMIP5 experiment. Geophys. Res. Lett., 40, 5212-5217, doi:10.1002/grl.50956.

Shinoda, M., and Y. Yamaguchi, 2003: Influence of soil moisture anomaly on temperature in the Sahel: A comparison between wet and dry decades. J. Hydrometeor., 4, 437-447, doi:10.1175/ 1525-7541(2003)4<437:IOSMAO >2.0.CO;2.

Stegehuis, A., R. Vautard, P. Ciais, R. Teuling, M. Jung, and P. Yiou, 2013: Summer temperatures in Europe and land heat fluxes in observation-based data and regional climate model simulations. Climate Dyn., 41, 455-477, doi:10.1007/ s00382-012-1559-x.

Sutton, R. T., B.-W. Dong, and J. M. Gregory, 2007: Land/sea warming ratio in response to climate change: IPCC AR4 model results and comparison with observations. Geophys. Res. Lett., 34, L02701, doi:10.1029/2006GL028164.

Tang, Q., and G. Leng, 2013: Changes in cloud cover, precipitation, and summer temperature in North America from 1982 to 2009. J. Climate, 26, 1733-1744, doi:10.1175/JCLI-D-12-00225.1.

- - — , and P. Ya. Groisman, 2012: European hot summers associated with a reduction of cloudiness. J. Climate, 25, 36373644, doi:10.1175/JCLI-D-12-00040.1.

Teuling, A. J., and Coauthors, 2009: A regional perspective on trends in continental evaporation. Geophys. Res. Lett., 36, L02404, doi:10.1029/2008GL036584.

Tout, D. G., 1987: Precipitation-temperature relationship in England and Wales summers. Int. J. Climatol., 7, 181-184, doi:10.1002/joc.3370070208.

Trenberth, K. E., and D. J. Shea, 2005: Relationships between precipitation and surface temperature. Geophys. Res. Lett., 32, L14703, doi:10.1029/2005GL022760. 
Vautard, R., and Coauthors, 2007: Summertime European heat and drought waves induced by wintertime Mediterranean rainfall deficit. Geophys. Res. Lett., 34, L07711, doi:10.1029/2006GL028001.

Wentz, F. J., L. Ricciardulli, K. Hilburn, and C. Mears, 2007: How much more rain will global warming bring? Science, 317, 233235, doi:10.1126/science.1140746.

Wu, R., J. Chen, and Z. Wen, 2013: Precipitation-surface temperature relationship in the IPCC CMIP5 models. Adv. Atmos. Sci., 30, 766-778, doi:10.1007/s00376-012-2130-8.
Zampieri, M., F. D'Andrea, R. Vautard, P. Ciais, N. de NobletDucoudré, and P. Yiou, 2009: Hot European summers and the role of soil moisture in the propagation of Mediterranean drought. J. Climate, 22, 4747-4758, doi:10.1175/ 2009JCLI2568.1.

Zhao, W., and M. A. K. Khalil, 1993: The relationship between precipitation and temperature over the contiguous United States. J. Climate, 6, 1232-1236, doi:10.1175/1520-0442(1993)006<1232: TRBPAT $>2.0 . \mathrm{CO} ; 2$. 